NBER WORKING PAPER SERIES

\title{
A SURVEY OF GLOBAL IMPACTS OF CLIMATE CHANGE: REPLICATION, SURVEY METHODS, AND A STATISTICAL ANALYSIS
}

William D. Nordhaus

Andrew Moffat

Working Paper 23646

http://www.nber.org/papers/w23646

\author{
NATIONAL BUREAU OF ECONOMIC RESEARCH \\ 1050 Massachusetts Avenue \\ Cambridge, MA 02138
}

August 2017

This research was supported by US National Science Foundation Award GEO-1240507 and with support from a Carnegie Corporation Fellowship (Nordhaus). Nordhaus and Moffat declare they have no relevant financial conflicts of interest. The opinions and characterizations in this piece are those of the authors and do not necessarily represent official positions of the United States Government or the National Bureau of Economic Research. The authors declare no financial conflict of interests with this research. The authors received corrections to earlier estimates from Richard Tol as described for the individual studies below.

NBER working papers are circulated for discussion and comment purposes. They have not been peer-reviewed or been subject to the review by the NBER Board of Directors that accompanies official NBER publications.

(C) 2017 by William D. Nordhaus and Andrew Moffat. All rights reserved. Short sections of text, not to exceed two paragraphs, may be quoted without explicit permission provided that full credit, including $\odot$ notice, is given to the source. 
A Survey of Global Impacts of Climate Change: Replication, Survey Methods, and a Statistical Analysis

William D. Nordhaus and Andrew Moffat

NBER Working Paper No. 23646

August 2017

JEL No. C8,Q5,Q54

\begin{abstract}
The present study has two objectives. The first is a review of studies that estimate the global economic impacts of climate change using a systematic research synthesis (SRS). In this review, we attempt to replicate the impact estimates provided by Tol $(2009,2014)$ and find a large number of errors and estimates that could not be replicated. The study provides revised estimates for a total of 36 usable estimates from 27 studies. A second part of the study performs a statistical analysis. While the different specifications provide alternative estimates of the damage function, there were no large discrepancies among specifications. The preferred regression is the median, quadratic, weighted regression. The data here omit several important potential damages, which we estimate to add $25 \%$ to the quantified damages. With this addition, the estimated impact is $-2.04( \pm 2.21) \%$ of income at $3{ }^{\circ} \mathrm{C}$ warming and $-8.06( \pm 2.43) \%$ of income at $6{ }^{\circ} \mathrm{C}$ warming. We also considered the likelihood of thresholds or sharp convexities in the damage function and found no evidence from the damage estimates of a sharp discontinuity or high convexity.
\end{abstract}

William D. Nordhaus

Yale University, Department of Economics

28 Hillhouse Avenue

Box 208264

New Haven, CT 06520-8264

and NBER

william.nordhaus@yale.edu

Andrew Moffat

Embassy of the US

Beijing, China

andrew.s.moffat@gmail.com 


\section{Introduction}

Economic models predict that climate change will have significant effects on economic activity in several ways. Key sectors are agriculture, coastal communities due to sea-level rise, health, ecosystems, and energy systems. The International Panel on Climate Change undertook several surveys of the overall economic impacts of climate change in the Second through Fifth Assessment Reports. In the Fourth Report, the IPCC stated that "Global mean losses could be 1 to $5 \%$ of GDP for $4^{\circ} \mathrm{C}$ of warming." (IPCC, Fourth Assessment Report, Impacts, 2007, section 5.7). The Fifth Assessment Report does not include a numerical estimate but has a table of impacts (see below). The summary in the Fifth Assessment Report states, "In sum, estimates of the aggregate economic impact of climate change are relatively small but with a large downside [sic, but presumably meaning upside] risk." (IPCC, Fifth Assessment Report, Impacts, 2013, p. 692)

The first part of this study is a review of estimates of the global impacts of climate change. There have been several surveys of impacts by researchers. One of the most influential was Tol (2009), which contained a survey of the literature and a statistical analysis. This study was widely criticized as containing significant errors. Tol published a corrections (Tol 2014), which also had errors, and the journal published an Editorial Statement (2015) describing the errors and referring interested scholars to the IPCC Fifth Assessment Report. There was a closely related table in the IPCC Fifth Assessment Report, which was almost identical to Tol's latest summary in Tol (2014), but the source was not attributed. ${ }^{1}$ This report will concentrate on the original Tol article and the 2014 revision.

There are concerns that inaccurate estimates have affected the scholarly and policymakers' views of the damages resultant from climate change impacts. Given the multiple errors contained in the Tol survey, and the apparent republication of his estimates in the IPCC Fifth Assessment Report, we believe that an independent look at the methods and range of damage estimates is of great importance. There is a growing body of evidence on the difficulty of replicating studies, and this is clearly essential to areas of interest as centrally important as climate change damages (see particularly Ioannidis 2016).

Given the already large and growing body of literature surrounding the impacts of climate change, we selected two different approaches to a survey of the academic literature on impacts. We first undertook a classical systematic research synthesis, or "SRS." It turns out that this approach, as we will explain below, had limited success. We therefore augmented the SRS with other information. We also reviewed the estimates in the various Tol surveys, particularly the final tabulation in Tol (2014), to see if we could bring a close to this long-running saga.

The second contribution of this study is to examine alternative specifications and estimates that can be used for empirical damage functions in integrated assessment models (IAMs). The approach was to use the 36 usable estimates and treat them as data

1 IPCC, Impacts (2014), Supplementary Material, Chapter 10, p. SM10-4. 
drawn from an underlying damage function. The preferred regression is the median quadratic weighted regression. The estimated impact from the preferred regression is $1.63 \%$ of income at $3{ }^{\circ} \mathrm{C}$ warming and $6.53 \%$ of income at a $6{ }^{\circ} \mathrm{C}$ warming. We make a judgmental adjustment of $25 \%$ to cover unquantified sectors. The reasons for this adjustment were provided in Nordhaus and Sztorc (2013) and are given in the Appendix. With this adjustment, the estimated impact is $-2.04( \pm 2.21) \%$ of income at $3{ }^{\circ} \mathrm{C}$ warming and $-8.16( \pm 2.43) \%$ of income at a $6^{\circ} \mathrm{C}$ warming. An additional major conclusion concerns the likelihood of thresholds or sharp convexity in the damage function. A variety of tests suggest that there is no indication from the damage estimates of a sharp discontinuity or high convexity.

We add an important note on the sign convention on "damages" and "impacts." In this study, damages and impacts are measured with a negative sign. Therefore, the preferred estimate is for an impact or damage of $-2.04 \%$ of income at $3{ }^{\circ} \mathrm{C}$ warming. Sometimes, damages are measured as a positive number. This confusion is probably one of the reasons why impact or damage estimates are incorrectly tabulated.

We close with a note of urgency on the importance of greater attention to damage estimates. This point was also emphasized in a recent report of a panel of the National Academy of Sciences (NAS) on the social cost of carbon: "In the longer term, the Interagency Working Group [of the US government] should develop a damages module that meets the overall criteria for scientific basis, transparency, and uncertainty characterization: 1. It should disaggregate market and nonmarket climate damages by region and sector, with results that are presented in both monetary and natural units and that are consistent with empirical and structural economic studies of sectoral impacts and damages. 2. It should include representation of important interactions and spillovers among regions and sectors, as well as feedbacks to other modules. 3. It should explicitly recognize and consider damages that affect welfare either directly or through changes to consumption, capital stocks (physical, human, natural), or through other channels. 4. It should include representation of adaptation to climate change and the costs of adaptation. 5. It should include representation of non-gradual damages, such as those associated with critical climatic or socioeconomic thresholds." (National Research Council 2017, p. 147)

The present study is but a tiny step down the road recommended by the NAS committee. It starts by compiling an accurate list of the global studies to date. Much more work is needed to fulfill the ambitious agenda laid out by the report.

\section{Methodology}

\section{Introduction to research synthesis and meta-analysis}

There are two main methods for research syntheses: narrative and quantitative. Each of these approaches has advantages as well as disadvantages. The narrative approach is the most common one for literature review because it is straightforward, especially when the researcher is familiar with the literature on the topic. But this approach is susceptible 
to the subjective judgment of the researcher and may fail to examine characteristics of studies as potential reasons for disparate results (Wolf 1986).

The quantitative approach uses a systematic approach to reviewing a topic. Quantitative research synthesis can take different forms, generally grouped into three categories: (1) meta-analysis (which we will confine to classical meta-analysis with a well-defined sampled population); (2) research synthesis with a clear sampling procedure, which we call "systematic research synthesis"; (3) and research synthesis without a clear sampling procedure, which we call "non-systematic research synthesis." While the quantitative approach is not immune to criticisms, the problem of subjectivity is generally less serious if the researcher conducts the analysis in a systematic fashion.

The history of quantitative research synthesis goes back to early $20^{\text {th }}$ century. The first such synthesis appears to be Karl Pearson's study in 1904 in which he combined five separate samples in analyzing the correlation between enteric fever inoculation and mortality (Pearson 1904). Other examples of early work in this area include Tippett (1931), Birge (1932), Fisher (1932), Cochran (1937), and Mosteller and Bush (1954).

The term "meta-analysis" was coined by Gene V. Glass in a paper in 1976, in which he defined a meta-analysis as "the analysis of analyses ... [that is,] the statistical analysis of a large collection of analysis results from individual studies for the purpose of integrating the findings" (Glass 1976). Since then, meta-analysis techniques have been greatly advanced and widely applied in fields such as medicine, education, and psychology (for some examples, see Glass, McGaw, and Smith 1981; Hunter, Schmidt, and Jackson 1982; Rosenthal 1984; Hedges and Olkin 1985). ${ }^{2}$ The term meta-analysis is now widely used for a compilation of studies even though it does not have a probabilistic interpretation, but we propose a stricter definition below.

There is a long tradition of using meta-analysis in the biomedical literature, largely because clinical trials of new drugs are expensive to conduct and meta-analyses are a cost-effective way for synthesizing individual studies. A numerical example will illustrate the approach. Assume that five independent studies have been conducted for examining the effectiveness of a drug XYZ. The results of the studies are shown in Table 1 . No study shows effectiveness at a 1\% probability, while three show effectiveness at a $5 \%$ probability. However, when we combine the five studies, they show effectiveness with high confidence $(\mathrm{p}=0.04 \%)$. This example is one of a classic meta-analysis because the studies are drawn from the same distribution.

${ }^{2}$ For a more detailed history of meta-analysis, see Cooper and Hedges (1994). 


\begin{tabular}{|l|ccccc|}
\hline \multicolumn{1}{|c|}{ Study } & Test value & Observations & t-statistic & p value \\
\hline A & 0.80 & 40 & 1.07 & 0.2907 \\
B & 1.02 & 90 & 2.00 & 0.0489 \\
C & 1.69 & 30 & 2.16 & 0.0388 \\
D & 0.50 & 20 & 0.42 & 0.6775 \\
E & 1.52 & 50 & 2.13 & 0.0378 \\
Combined & 1.13 & 230 & 3.57 & 0.0004 \\
\hline
\end{tabular}

Table 1: Example of a combined test for meta-analysis of effectiveness of drug XYZi

This simple example illustrates some key points about meta-analysis. First, in synthesizing the estimates from separate studies, it is important to ensure that those estimates are independent. Second, the sample sizes of different studies in a metaanalysis give important information in the calculation of the combined statistic. All else equal, the sample size of a study is a proxy of the reliability of its results. Third, a metaanalysis can reveal more accurate results than from individual studies; in the example above, even though four out of five studies do not report statistically significant effects, the combined test shows a significant effect. Finally, and most important for the topic at hand, the requirements for deriving a statistical interpretation of a synthesis of different studies is very demanding and unlikely to be met in many circumstances.

We emphasize that our definition of "meta-analysis" is narrower than the standard usage in economics and many other areas. We limit this term to a collection of studies where the studies are drawn from a well-defined population; and where the samples can be deemed independent (or where the dependence is clearly defined). Under this definition, the studies can be combined using standard statistical tools.

\section{The role of meta-analyses and research syntheses in economics}

A central issue for thinking about meta-analysis and research summaries concerns the population from which the studies is drawn. In classical meta-analysis, such as studies of the effect of anti-depressants discussed above, the sample is in principle the adult population recruited for clinical trials. If the samples are from the same population and are independent, and if the treatment protocols are identical, then it is appropriate to combine those samples into a meta-sample, and this larger sample can estimate the effect of the drug more precisely than the individual studies.

There is a growing literature that presents "meta-analyses" in economics. Stanley's survey cites meta-analyses of union wage premiums, recreation benefits, education and productivity, minimum wage effects, gasoline demand elasticities, the benefits of endangered species, and of Ricardian equivalence (Stanley 2001). We have identified 46 studies with "meta-analysis" in the titles of 245 economics journals covered by JSTOR. 
None of these were classical meta-analyses. A very small number had properties where the populations were potentially homogeneous, but none exploited this property to derive improved estimates. About half of the studies were research summaries, often employing regression analyses. They are "quantitative research syntheses," some systematic, some non-systematic. However, the conditions for an appropriate metaanalysis almost never apply for research in economics and environmental economics. Many of them look at the same data (for example the Current Population Survey or government data on productivity) and the difference might be the econometric technique or the sample period.

An example of something mislabeled as a meta-analysis is Stanley's study of Ricardian equivalence (Stanley 1998). He selects his sample as all studies included in EconLit that refer to "Ricardian equivalence," claim to test Ricardian equivalence, and report the corresponding test statistic. There is no discussion about the overlap of the underlying data (e.g., years, countries, macro v. micro). Rather, the emphasis is on testing the influence of the equation specification on the statistical significance. This study therefore clearly qualifies as a systematic research synthesis but not as a meta-analysis in our sense. We do not downplay the importance of systematic research syntheses. These allow researchers to examine existing research in a way that may help avoid bias. But a probabilistic interpretation usually does not automatically apply and must be determined in each case.

The difference between meta-analysis and research synthesis can be illustrated for our subject, the impacts of climate change. For example, two studies might summarize the impacts of sea-level rise based upon the same underlying study. These estimates would clearly not be independent. Or a study might be an update of an earlier study by the same author. In this case, the author might have revised the estimates for some but not all sectors. These challenges imply that a research synthesis might be a useful summary of the literature, but it would generally not be appropriate to assume that the studies are independent. The major potential advantage of systematic research syntheses for impacts is to avoid subjectivity in the selection of studies. We will see below that this has been a major issue in current surveys.

\section{Systematic research summary for impacts of climate change}

\section{Systematic Research Summary}

It is immediately apparent that the different studies of the impacts of climate change do not qualify for a classic meta-analysis. The results clearly are not independent samples from a population.

Instead, we begin with a systematic research summary (SRS). We now describe the method by which we undertook the SRS for impacts. The starting point for any SRS is to define a research area and a universe to search. The universe to search for the present analysis was designated as platforms that aggregate relevant academic literature. The platforms assessed were EconLit, JSTOR, and Google Scholar. The first two are ones that have strict criteria on inclusion (primarily publication in a designated set of scholarly journals). Google Scholar is much more inclusive, but the set of criteria is not welldefined. 
Each of these platforms was tested to determine whether a search turned up most of the studies used in Tol (2014). EconLit and Google Scholar passed this first hurdle (although not with flying colors). JSTOR failed miserably, containing only two of the studies in question, so JSTOR was dropped from the list of search engines.

The two remaining platforms were then assessed based on our ability to use the platform for the present study. Keeping in mind that our research methodology would require us to go through each entry retrieved from our search string, we determined that EconLit provides a manageable number of entries while Google Scholar provides so many entries as to be unwieldy. Google Scholar would in principle be the preferred engine, as it captured the available body of literature more fully. However, the size of the resulting number was too large to be feasible within the scope of the present study. Given this constraint, the following SRS is based on those studies retrieved from EconLit alone. (See Appendix Table A-1 for the success of different search engines.)

The next step was to define the research area. While the general subject (impacts of climate change) was clear, generating a list of studies requires defining a string search, or list of keywords. Based on our experience and the studies included in Tol (2014), we tested several strings that might be included in the study. The general criterion was that the string should include all studies, but at the same time should yield a manageable number of results. To create this search string, we identified several key words and linking syntaxes, creating from these 21 unique search strings.

Each search string was run through the three databases, and we noted: (1) the number of total entries returned and (2) the number of studies from Tol (2014) included in the search string. The desired result was to optimize a function to have a large number under criterion (2) while having a relatively small number of studies to examine in (1). To keep the study manageable, we limited the number of studies to under 2000. The final search string used was as follows: "(damage OR impact) AND climate AND cost." This string generated nearly 1700 studies in EconLit. By contrast, the number of hits in Google Scholar was 2,800,000, while the number of hits in Google was 64,000,000.

The next step was to review the abstracts of each of these studies and determine the relevance of each to the present study, and our degree of confidence that the study was or was not relevant. ${ }^{3}$ This process of coding each study was done as precisely and as conservatively as possible to allow for the highest number of relevant studies to enter into our analysis. Of the 1700 identified studies, only 24 studies, or just over one percent of studies that passed the string test, were found to address global impacts from climate change. We then read the articles from the 24 studies that seemed likely candidates on the basis of their abstracts. From the 24 studies, only 11 provided enough information to determine global damages, of which only six were included in Tol (2014).

To summarize the results of the SRS: It turned out that using the approach of a formal SRS was of limited value. To begin with, the field is too diffuse to define a wellidentified subject. Unlike a subject like "The effects of non-steroidal anti-inflammatory drugs on cancer sites other than the colon and rectum," "impacts of climate change"

${ }^{3}$ See Table A-2 for our full coding system. 
covered too much ground. It turned up too many sectors, regions, countries, types of studies, policy proposals, and so forth. While Google Scholar turned up virtually all the studies that we knew, it was impractical.

A further finding from our SRS concerned the results when we limited the number of studies to a manageable number (fewer than 2000 abstracts). In this case, again because of the diffuse character of the field, only $1 / 2 \%$ of studies turned out to contain useful information. While these studies were additions to the list of previously identified studies, it was an extremely small yield.

Finally, and most interesting, is that the SRS missed a substantial fraction of the previously identified studies. This occurred because they were in obscure journals or books, or in fields that were not covered by either EconLit or JSTOR.

\section{Non-systematic Research Summary}

Given the limited ability of our SRS methodology to return a useful universe of studies, we combined it with a second approach, known as a "non-systematic research summary." In this approach, the universe of studies was selected by a combination of formal and informal methods, such as the SRS above, the results of the Tol survey, and other studies that were known to the researchers.

In our case, we included in our research summary those studies included in Tol (2014), plus those relevant studies found in our SRS but not included in Tol (2014). To this end, we reviewed all studies included in Tol (2014) as he expanded the list of relevant studies from his 2009 article. A summary of our findings is included in our results section, and more detailed accounts of the reviewed studies from Tol (2014) can be found in Appendix Table A-3.

Most of the studies from Tol (2014) and our SRS provided explicit estimates of global damages. However, four studies provided only regional estimates, and we calculated global damages ourselves. ${ }^{4}$ There were differences between our results and

4 These studies were: Maddison 2003, Rehdanz and Maddison 2005, Maddison and Rehdanz 2011, and Kemfert 2001. In these four studies, the authors estimated damages for different sets of between 67 to 88 nations and eight to 11 regions. We estimated global damages for each study by aggregating the product of each nation's individual damages and its share of global income. Where national GDP and per capita GDP figures were required for our calculations, we used GDP in 2010 prices from the IMF, in international USD. To examine differences between current and future damage estimates, we converted all per capita and national GDP data to their future values using scaling factors derived from the FUND model's regional growth rates. Income data was scaled to the relevant year in each study. We are indebted to David Anthoff for providing these figures. The regional disaggregation was found using the model's technical tables (Tol and Anthoff, 2014). 
Tol's that may have arisen because he used a different methodology. However, he did not provide his methods, so his results could not be replicated. ${ }^{5}$

In undertaking our replication, it has proven extremely difficult to determine the results for many of the studies. One set of studies states clearly the global results for a given temperature change. A second set provides estimates by region, and these can then be aggregated for a given distribution of world output. A third set does not provide full information, and for these we needed to go to the authors to find the estimates. Even for these, the base year for the temperature is not uniform and is not always clear. So, while we have made great efforts to verify the results, even these are likely to contain residual errors.

Finally, we note that the results are usually cited as impacts on "global GDP." This nomenclature is somewhat misleading, because the concepts often differ from standard GDP measures. Most damage estimates include non-market output (such as health or ecosystem damages), and some output estimates are closer to net rather than gross, or use consumption or the consumption-equivalent of utility as the output estimate. These differences will be important for the numerator (damages) but generally the adjustments for the denominator (output) will be minimal. The only exception to the statement about the denominator is that it will make a substantial difference whether output is measured at market exchange rates (MER) or at purchasing power parity (PPP) exchange rates. We take the PPP approach whenever there is a choice.

\section{Results}

We have collected the results of the studies from Tol and from our systematic and non-systematic research syntheses in Table 2 . Each row is a different global damage estimate, so studies with more than one estimate are represented in multiple rows. The first group is from Tol, while the second are ones identified in our SRS and not in Tol.

After introducing the study's author and year, the next two columns report the status. They are grouped into four categories according to the status of the impact estimate: correct in Tol (Y), incorrect in Tol (Err), unable to replicated (NR), or omitted (O). Table 5 collates the totals in each category for the 2009 and 2014 studies.

The columns indicate the global average temperature increase above pre-industrial levels in degrees $\mathrm{C}$ and the resultant impact to global income or output in percentage terms. To provide a glimpse of how estimates have been revised over time for each study, we have included estimates from Tol (2009), Tol (2014), and the present analysis. There are 31 different damage estimates. Of these, six were generated by the SRS but not included in Tol's survey, and 25 were from the expanded Tol list.

Table 3 shows the studies that were added for the statistical analysis in the next section. These included three integrated assessment models that include damage modules. Two of the estimates were calculated from the MUP study (Gillingham 2015), and the other was provided by Chris Hope (see the discussion in Table A-3).

${ }^{5}$ See Appendix Table A-4 for a complete list of countries in each region and for each region's share of global income. 
Since the number of studies and estimates is confusing, we have summarized the numbers in Table 4.

Table 5 shows an assessment of the accuracy and replicability of the two Tol studies using the estimates in the current study as a benchmark. Of the original 14 impact estimates, 7 were incorrect or not replicated. Of the 21 impact estimates in the 2014 study, 10 were incorrect or could not be replicated.

Most of the cases of error or lack of replicability arose because the primary source did not provide a clear and unambiguous estimate of global damages. In some cases, Tol did not provide the methodology for deriving estimates, so the difference may arise due to different methods. Some cases (such as the wrong sign for impacts or taking the wrong scenarios when the preference was clearly stated) were just plain mistakes. We also note that some of our estimates could not be derived from the primary source. In several cases, we sought and received clarifications or estimates from the authors, and these are the basis of our estimates. (See the discussion in Table A-3 for details.) 


\begin{tabular}{|c|c|c|c|c|c|c|c|c|c|}
\hline \multirow[t]{2}{*}{ Study } & \multirow[t]{2}{*}{ Year } & \multirow{2}{*}{\begin{tabular}{c|}
$\begin{array}{c}\text { Status for } \\
\text { temp }\end{array}$ \\
2009 \\
\end{tabular}} & $\begin{array}{l}\text { Status for } \\
\text { temp }\end{array}$ & \multicolumn{2}{|c|}{ Tol (2009) } & \multicolumn{2}{|c|}{ Tol (2014) Final } & \multicolumn{2}{|c|}{ In This Study } \\
\hline & & & 2014 & Degree & Damage & Degree & Damage & Degree & Damage \\
\hline \multicolumn{10}{|c|}{ Studies from Tol (2009) or Tol (2014) } \\
\hline Nordhaus a & 1994 & $\mathrm{Y}$ & $\mathrm{Y}$ & 3.00 & -1.30 & 3.00 & -1.30 & 3.00 & -1.33 \\
\hline Nordhaus b & 1994b-i & Err & $\mathrm{Y}$ & 3.00 & -4.80 & 3.00 & -3.60 & 3.00 & -3.60 \\
\hline Nordhaus b & 1994b-ii & 0 & 0 & na & na & na & na & 6.00 & -10.40 \\
\hline Fankhauser & 1995 & Y & $\mathrm{Y}$ & 2.50 & -1.40 & 2.50 & -1.40 & 2.50 & -1.40 \\
\hline Tol & 1995 & Y & $\mathrm{Y}$ & 2.50 & -1.90 & 2.50 & -1.90 & 2.50 & -1.90 \\
\hline Nordhaus and Yang & 1996 & Y & $\mathrm{Y}$ & 2.50 & -1.70 & 2.50 & -1.70 & 2.50 & -1.70 \\
\hline Pambeck and Hope & 1996 & Err & NR & 2.50 & 2.50 & 2.50 & -2.50 & 2.20 & ? \\
\hline $\begin{array}{l}\text { Mendelsohn, } \\
\text { Schlesinger, and } \\
\text { Williams }\end{array}$ & $2000-\mathrm{i}$ & Err & 0 & 2.50 & 0.00 & na & na & 2.20 & 0.03 \\
\hline $\begin{array}{l}\text { Mendelsohn, } \\
\text { Schlesinger, and } \\
\text { Williams }\end{array}$ & 2000-ii & Err & 0 & 2.50 & 0.01 & na & na & 2.20 & 0.07 \\
\hline $\begin{array}{l}\text { Mendelsohn, Morrison, } \\
\text { Schlesinger, and } \\
\text { Andronova }\end{array}$ & 2000-iii & 0 & Err & na & na & 2.50 & 0.00 & 2.00 & 0.08 \\
\hline $\begin{array}{l}\text { Mendelsohn, Morrison, } \\
\text { Schlesinger, and } \\
\text { Andronova }\end{array}$ & 2000-iv & 0 & Err & na & na & 2.50 & 0.01 & 3.50 & 0.01 \\
\hline Nordhaus and Boyer & 2000 & Y & $\mathrm{Y}$ & 2.50 & -1.50 & 2.50 & -1.50 & 2.50 & -1.50 \\
\hline Tol & 2002 & $\mathrm{Y}$ & $\mathrm{Y}$ & 1.00 & 2.30 & 1.00 & 2.30 & 1.00 & 2.30 \\
\hline Maddison & 2003 & NR & NR & 2.50 & -0.10 & 2.50 & -0.10 & 3.10 & -2.22 \\
\hline Rehdanz and Maddison & $2005-i$ & $\mathrm{Y}$ & $\mathrm{Y}$ & 1.00 & -0.40 & 1.00 & -0.40 & 1.24 & -0.32 \\
\hline Rehdanz and Maddison & 2005-ii & 0 & 0 & na & na & na & na & 0.84 & -0.32 \\
\hline Hope & 2006 & Err & Err & 2.50 & 0.90 & 2.50 & -0.90 & 2.50 & -0.58 \\
\hline Nordhaus & 2006-i & Err & Err & 2.50 & -0.90 & 2.50 & -0.90 & 3.00 & 0.90 \\
\hline Nordhaus & 2006-ii & 0 & $\mathrm{Y}$ & NA & NA & 3.00 & -1.10 & 3.00 & -1.05 \\
\hline Nordhaus & 2008 & 0 & $\mathrm{Y}$ & NA & $\mathrm{NA}$ & 3.00 & -2.50 & 3.00 & -2.49 \\
\hline Maddison and Rehdanz & 2011 & 0 & NR & NA & $\mathrm{NA}$ & 3.20 & -11.50 & 4.00 & -17.80 \\
\hline Bosello et al. & 2012 & 0 & $\mathrm{Y}$ & NA & $\mathrm{NA}$ & 1.90 & -0.50 & 1.92 & -0.50 \\
\hline $\begin{array}{l}\text { Roson and van der } \\
\text { Mensbrugghe }\end{array}$ & $2012-i$ & 0 & NR & NA & $\mathrm{NA}$ & 2.90 & -1.80 & 3.10 & -2.14 \\
\hline $\begin{array}{l}\text { Roson and van der } \\
\text { Mensbrugghe }\end{array}$ & 2012-ii & 0 & Err & NA & NA & 5.40 & -4.60 & 5.50 & -6.05 \\
\hline Nordhaus & 2013 & 0 & Err & NA & $\mathrm{NA}$ & 2.90 & -2.00 & 3.00 & -2.25 \\
\hline \multicolumn{10}{|c|}{ Studies added from research synthesis from this study } \\
\hline Cline & $1992-\mathrm{i}$ & 0 & 0 & NA & $\mathrm{NA}$ & NA & $\mathrm{NA}$ & 2.50 & -1.10 \\
\hline Cline & 1992-ii & 0 & 0 & NA & $\mathrm{NA}$ & NA & $\mathrm{NA}$ & 10.00 & -6.00 \\
\hline Nordhaus & 2010 & 0 & 0 & NA & $\mathrm{NA}$ & NA & $\mathrm{NA}$ & 3.40 & -2.80 \\
\hline Dellink & 2012 & 0 & 0 & NA & $\mathrm{NA}$ & NA & $\mathrm{NA}$ & 2.50 & -1.10 \\
\hline Kemfert & 2012 & 0 & 0 & NA & $\mathrm{NA}$ & NA & $\mathrm{NA}$ & 0.25 & -0.17 \\
\hline Hambel & 2012 & 0 & 0 & NA & $\mathrm{NA}$ & NA & $\mathrm{NA}$ & 1.00 & -0.30 \\
\hline
\end{tabular}

Table 2. Impact studies in Tol and the current studyii

Note that a negative sign on damages or impacts signifies that warming reduces output. 
Studies added after research synthesis for statistical analysis

\begin{tabular}{|l|l|rr|}
\hline \multicolumn{1}{|c|}{ Study } & Year & Degree & \multicolumn{1}{c|}{ Damage } \\
\hline FUND & $2015-\mathrm{i}$ & 1.99 & 0.00 \\
FUND & $2015-\mathrm{ii}$ & 2.98 & 0.00 \\
FUND & $2015-\mathrm{iii}$ & 3.92 & 0.01 \\
WITCH & $2015-\mathrm{i}$ & 2.00 & -1.84 \\
WITCH & $2015-\mathrm{ii}$ & 3.00 & -3.72 \\
WITCH & $2015-\mathrm{iii}$ & 4.00 & -6.25 \\
PAGE09 & $2017-\mathrm{i}$ & 2.00 & -0.77 \\
PAGE09 & $2017-$-ii & 3.00 & -1.32 \\
PAGE09 & $2017-$ iii & 4.00 & -2.59 \\
\hline
\end{tabular}

Table 3. Studies added for statistical analysis

\begin{tabular}{|l|r|r|}
\hline Study & Number studies & \multicolumn{2}{c|}{$\begin{array}{c}\text { Number } \\
\text { estimates* }\end{array}$} \\
\hline Tol 2009 & 13 & 13 \\
Tol 2014 & 18 & 24 \\
Tol plus SRS & 23 & 29 \\
Total for statistical study & 27 & 38 \\
\hline
\end{tabular}

Table 4. Studies and estimates reviewed in this report ${ }^{\mathrm{iii}}$

*One estimate was unable to be validated and was omitted.

\begin{tabular}{|l|c|c|}
\hline Category & 2009 & 2014 \\
\hline Err = Errors & 6 & 6 \\
NR = Unable to replicate & 1 & 4 \\
O = Omitted from survey & 17 & 10 \\
Y = Confirm estimate & 7 & 11 \\
\hline
\end{tabular}

Table 5. Overall assessment of accuracy of estimates in Tol (2009) and Tol (2014) ${ }^{\mathrm{iv}}$ 


\section{Statistical Analysis}

It will be useful to synthesize the different studies to provide a central estimate, using the individual studies as "data." This approach is clearly warranted for standard metaanalyses, such as in the case of studies which report independent clinical trials. In the present situation, the results of the chosen studies are sometimes dependent, so treating them as independent data points is less clearly appropriate. We have therefore made adjustments to reflect the potential dependence. Additionally, in our primary estimates, we have assumed that there is a true relationship, and that the data points are drawn from that relationship with errors of measurement of the damages, but not of the temperature changes themselves.

The approach we take is the following: We begin with the estimates shown in Tables 2 and 4. ${ }^{v}$ These yield 36 usable estimates from 27 studies.

We then determine a set of weights for each study, from 0 to 1 . A weight of 1 is given to the latest versions of estimates that used independent methods which, in our view, were appropriate for estimating damages. We downgraded either earlier versions of estimates (such as earlier versions of DICE model estimates), studies that primarily relied on other studies, and studies that used what we view as uninformative methods. As an example of the latter, our opinion is that studies relating current incomes to "happiness" and weather provide little information about long-run impacts of climate change, so these receive a low weight.

Figure 1 shows a scatter plot of the data points. Visually, the immediate impression is that there are many studies of theoretical temperature increases in the 2 to $4{ }^{\circ} \mathrm{C}$ range, and that they cluster in the range of a loss of 0 to $4 \%$ of global output.

Table 6 shows the distribution of weights for the 38 estimates. 10 studies received full weight, while 17 were omitted or accorded minimal weights. Appendix Table A-6 shows these estimates and weights in detail. We preview at this point that the weighting made little difference to the results, and, while it introduces a degree of subjectivity, it does not skew the results.

\begin{tabular}{|r|r|r|r|r|}
\hline Value & Count & Percent & $\begin{array}{r}\text { Cumulative } \\
\text { Count }\end{array}$ & $\begin{array}{r}\text { Cumulative } \\
\text { Percent }\end{array}$ \\
\hline 0.00 & 2 & 5 & 2 & 5 \\
0.10 & 16 & 42 & 18 & 47 \\
0.25 & 3 & 8 & 21 & 55 \\
0.30 & 6 & 16 & 27 & 71 \\
0.40 & 3 & 8 & 30 & 79 \\
0.50 & 2 & 5 & 32 & 84 \\
0.90 & 1 & 3 & 33 & 87 \\
1.00 & 5 & 13 & 38 & 100 \\
\hline Total & 38 & 100 & 38 & 100 \\
\hline
\end{tabular}

Table 6. Distribution of weights for included studies. ${ }^{\mathrm{i}}$ 


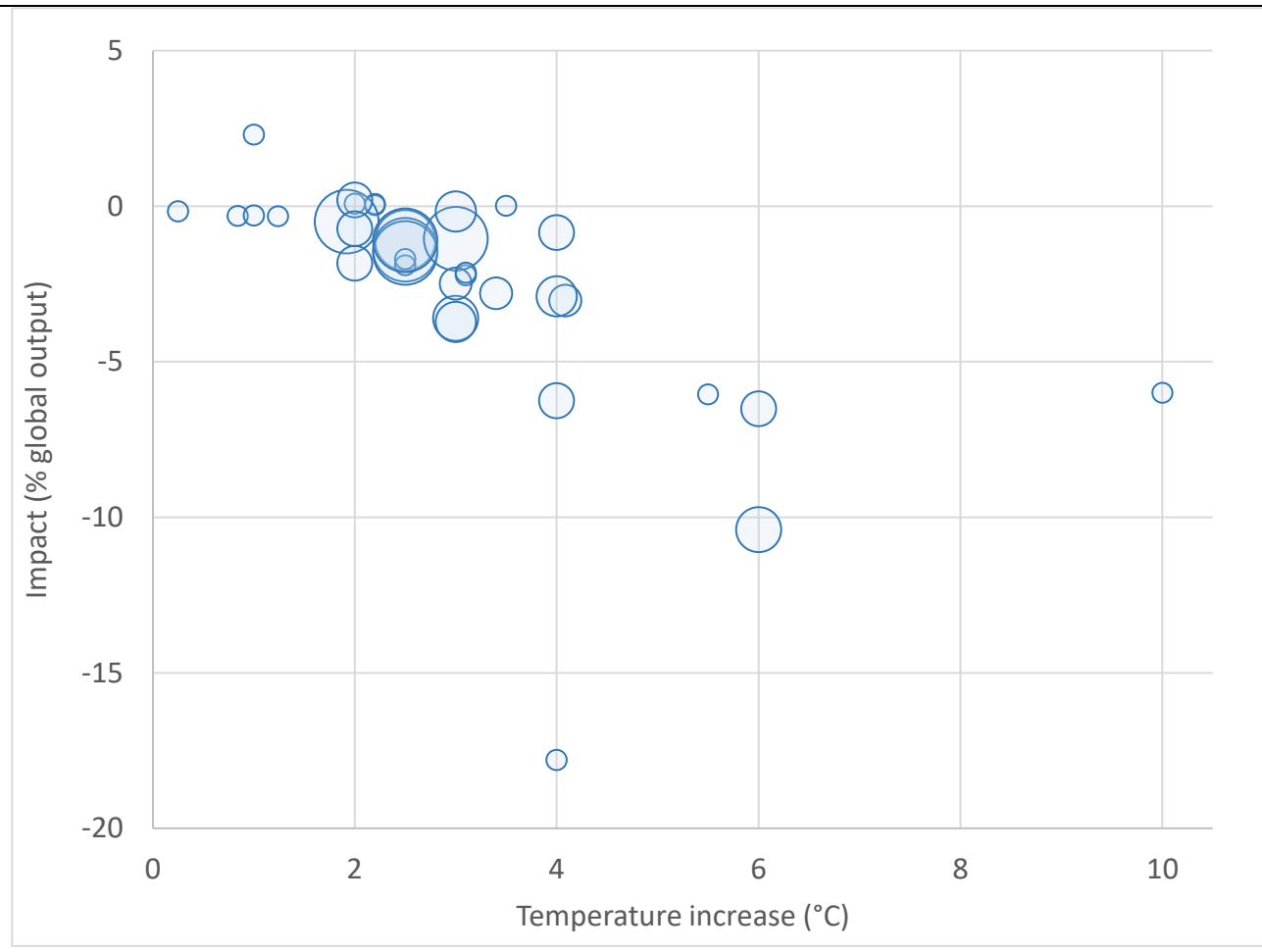

Figure 1. Scatter of results of all studies ${ }^{\text {vii }}$

Figure shows the results of 36 estimates with positive weight. The area of each circle represents its weight.

We then estimated several specifications of damage functions. These were as follows:

- Regression specifications: weighted and unweighted; ordinary least squares ("OLS") and quantile regression ("Median").

- Three alternative versions of polynomial: quadratic term only ("Quad"), linear and quadratic terms ("LinQuad"), and nonlinear with estimated exponent (“Expon").

- Omitting outliers from the top and bottom: For each of the first two sets of cases, we also ran regressions which omitted data starting from the bottom and from the top. For example, starting from the top, we omit estimates with temperature greater than $8^{\circ} \mathrm{C}$ because these are highly speculative and would have great weight in an OLS regression. We can also omit estimates with temperatures less than $2{ }^{\circ} \mathrm{C}$, because these are relatively unimportant for damage functions in the range of 3 to $6{ }^{\circ} \mathrm{C}$, which is most important for the end of the $21^{\text {st }}$ century. 
The most useful way to tabulate the results was to predict damages at 3 and $6{ }^{\circ} \mathrm{C}$. Table 7 tabulates the results by specification, and the full results are shown in Appendix Table A-7ABC.

Another way to visualize the implications of different specifications is shown in Figure 2. This shows the predictions from the regressions for seven different specifications along with the actual study results (the graph is slightly truncated for legibility).

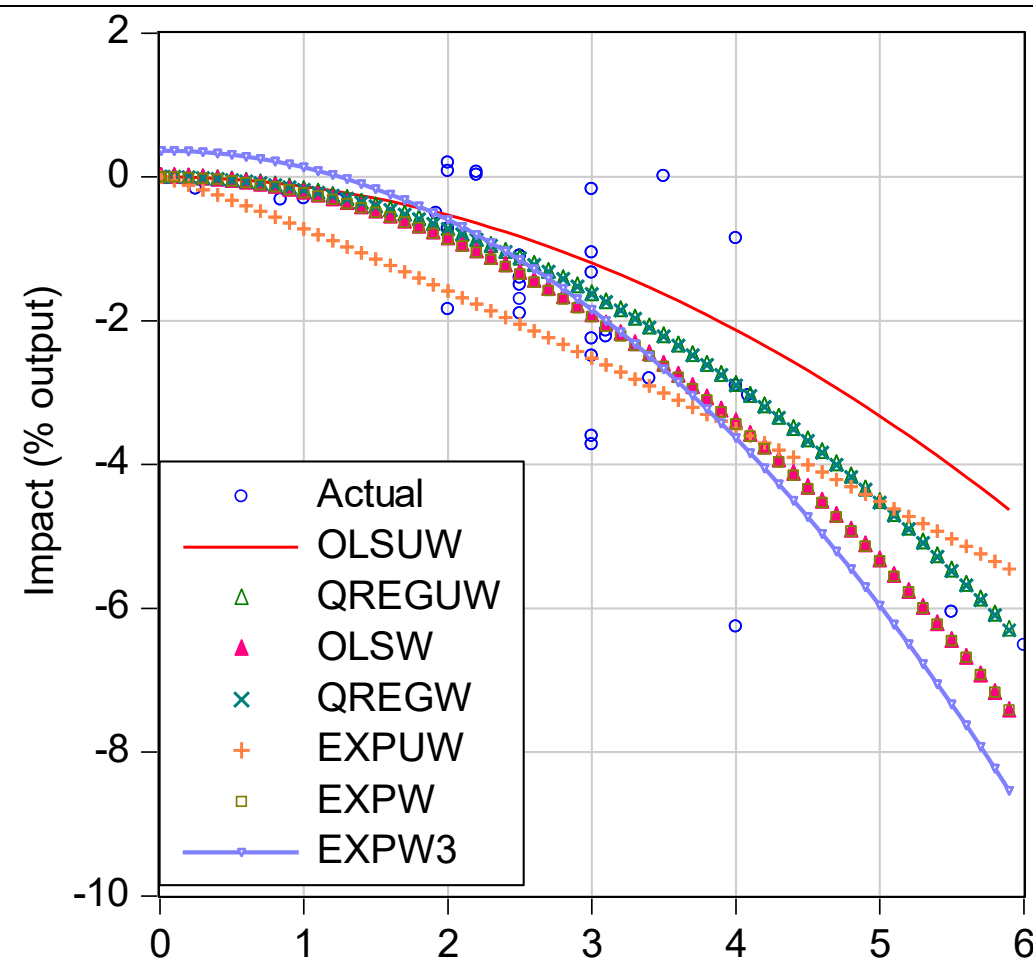

Temperature increase $\left({ }^{\circ} \mathrm{C}\right)$

Figure 2. Scatter plot of actual and alternative specifications viii

Key for predicted is OLS = ordinary least squares; $\mathrm{QREG}=$ median regression; $\mathrm{UW}=$ unweighted; $\mathrm{W}=$ weighted; EXP = with fitted exponent. EXPW3 adds a linear term to the polynomial. Impact $=$ from studies.

The authors' preferred regression is the median quadratic weighted regression. The impact is $-1.63( \pm 1.77) \%$ of income at $3{ }^{\circ} \mathrm{C}$ warming and $-6.53( \pm 1.95) \%$ of income at a $6{ }^{\circ} \mathrm{C}$ warming. Note that the errors reported here represent forecast errors in the preferred equation. If we include all specifications (last rows of the table), the impact 
is $-1.8( \pm 0.74) \%$ of income at $3{ }^{\circ} \mathrm{C}$ warming and $-6.7( \pm 3.0) \%$ of income at a $6{ }^{\circ} \mathrm{C}$ warming. We note as well that the weighted regressions give larger negative predictions (damages) than the unweighted regressions.

We make a judgmental adjustment of $25 \%$ to cover unquantified sectors. This adjustment is described in detail in Nordhaus and Sztorc (2013) and in the Appendix. With this adjustment, the estimated impact is $-2.04( \pm 2.21) \%$ of income at $3{ }^{\circ} \mathrm{C}$ warming and $-8.16( \pm 2.43) \%$ of income at a $6{ }^{\circ} \mathrm{C}$ warming.

A final important finding concerns the possibility of sharp thresholds in damages. Technically, this concerns the degree of convexity of the damage function. Many damage functions are assumed to be linear-quadratic (as for example in most versions of the DICE model). By contrast, some scholars believe that the damage function is more convex. An important example that has been used in policy discussions is an approach which assumes a sharp threshold at a temperature increase of $2{ }^{\circ} \mathrm{C}$; implicitly this implies a very sharp kink in the curve near that threshold. There is virtually no information on this question in the impacts literature, but we can test it using the results collected here.

Tests for thresholds or convexity are shown in Table 7 in the rows labeled "Exponent." This reports results of an equation of the form $D / Y=\alpha T^{\beta}+\gamma$. There are four versions of this: weighted and unweighted combined with ones with and without the linear term $(\gamma)$. Note that, implicitly, the quadratic version has no linear term. The estimate of $\beta$ averages 1.3 for four the different specifications. The four estimates of $\beta$ are shown as the estimate of c(2) in the last four rows of Appendix Table A-7C. The authors' preferred estimate would be a weighted regression with the linear term, which has an exponent of $\beta=1.15( \pm 0.28)$. This result is important because it indicates that the impact estimates suggest a convexity that is less than quadratic. Moreover it strongly rejects damage estimates with a sharp discontinuity or convexity (as would be represented by a high value of $\beta$ ). Instead, it appears that the quadratic or linear-quadratic is a reasonable way of approximating the results of the damage studies.

We can also examine the degree of polynomial in the FUND and PAGE09 models (from data supplied by their authors). In a linear-quadratic specification, the PAGE09 model has an exponent of $\beta=1.82( \pm 0.20)$. The FUND model is virtually linear over the range of observations used in the MUP study. 


\begin{tabular}{|l|c|c|c|}
\hline \multirow{2}{*}{ Specification } & \multicolumn{2}{|c|}{ Damage to temperature: } & \multirow{2}{*}{} \\
\cline { 2 - 3 } & $3{ }^{\circ} \mathrm{C}$ & $6{ }^{\circ} \mathrm{C}$ & \multirow{2}{*}{ Exponent } \\
\hline Quad & & & \\
Selected & & & \\
Mean & -1.81 & -7.22 & 2 \\
St. Dev. & 0.34 & 1.35 & 0 \\
Quad all & & & \\
All & & & \\
Mean & -1.55 & -6.18 & 2 \\
St. Dev. & 0.91 & 3.62 & 0 \\
LinQuad & & & \\
Selected & & & 1,2 \\
Mean & -1.99 & -6.99 & 0 \\
St. Dev. & 0.35 & 1.50 & \\
LinQuad & & & 1,2 \\
All & & & 0 \\
Mean & -2.03 & -7.30 & 1.23 \\
St. Dev. & 0.39 & 2.08 & 0.55 \\
Exponent $(\beta)$ & & & \\
Mean & -2.28 & -6.80 & \\
St. Dev. & 1.13 & 4.01 & \\
All & & & \\
Mean & -1.77 & -6.72 & \\
St. Dev. & 0.74 & 3.02 & \\
\hline
\end{tabular}

Table 7. Estimates of damages at 3 and $6^{\circ} \mathrm{C}$ according to different specifications ${ }^{\mathrm{ix}}$

The table shows estimates of the damage/output ratio according to different specifications. The specifications are: "Quad" includes only a quadratic term. "LinQuad" includes both linear and quadratic terms. "Exponent" is a nonlinear equation of the form $D / Y=\alpha T^{\beta}+\gamma$. "Selected" specifications are ones with at least 25 observations, while "All" are all specifications in that category. 


\section{Conclusion}

The present study is a contribution to understanding the damages that are likely to occur with future climate change. It focuses on two separate questions: a review of current studies, and a synthesis of these studies.

\section{Review of existing studies}

On the first question, a review of existing studies, we used two approaches. The first is a formal systematic research synthesis (SRS) in which we used different databases to find studies of impacts. It turns out that this was only partially successful, because the databases turned up either too small or too large a number of studies to be examined. We then turned to a research synthesis, which combined the results of the SRS with a list of existing studies, primarily from impact studies of Richard Tol. In the end, we found 36 usable estimates from 27 studies.

One question that had been raised by scholars was whether the Tol estimates were accurate. We therefore endeavored to replicate the estimates of the Tol studies. Of the original 14 estimates, 7 were found to be incorrect or not replicable. In the final revision in 2014 (a correction of a correction), we found that of 21 estimates, 10 were found to be inaccurate or not replicable. This result adds to the growing body of work that indicates the low rate of replicability in studies. This is of particular concern in the present case because the Tol survey was supposed to help researchers wade through a large literature.

We add one final note for researchers: Our investigations have found few cases in which the techniques of formal systematic research synthesis, and no cases of true metaanalyses, were used in economics. Our results are not encouraging in this respect. In effect, we never got to first base. We were unable to find a database of studies that met the twin criteria of (i) turning up all the studies that we know about and (ii) doing so with a universe of studies that was sufficiently small $(<2,000)$ to allow a careful review of their content. It might be that further refinements that sift through the numerous ( $>1$ million) results from Google Scholar or a similar comprehensive data set could improve our search results, but we have not found such a technique.

It is useful to have a compilation of global aggregate damage estimates from climate change. This study has evaluated the results from Tol $(2009,2014)$ and found significant errors or inability to replicate the results. We add to the literature by carefully documenting our methodology and making it readily available. Further studies can work toward building a general consensus of the literature by performing research summaries that are both comprehensive and objective.

\section{Statistical summary}

The second contribution of this study is to examine alternative specifications and estimates that can be used for empirical damage functions in integrated assessment models (IAMs). The approach was to use the 36 estimates and treat them as data drawn from an underlying damage function. We also used weights attached to each estimate that reflected the authors' judgement as to whether it contributed independent information 
about damages. Figure 1 above provides a visual display of the estimates and their weights.

Our statistical procedures used several different approaches to estimating damage functions. They were different combinations of weighted and unweighted regressions; ordinary least squares and median regressions; quadratic, linear-quadratic, and polynomial specifications; and limited samples to exclude temperature extremes.

Three major conclusions emerged from the estimates. First, while the specifications provided different estimates, there were no large discrepancies. The preferred regression is the median, quadratic, weighted regression. With a judgmental adjustment of $25 \%$ on top of the quantified estimates, the estimated impact is -2.04 $( \pm 2.21) \%$ of income at $3{ }^{\circ} \mathrm{C}$ warming and $-8.16( \pm 2.43) \%$ of income at a $6{ }^{\circ} \mathrm{C}$ warming.

A second major conclusion concerns the likelihood of thresholds or sharp convexity in the damage function. A variety of tests suggest that there is no indication from existing damage estimates of a sharp discontinuity or high (greater than quadratic) convexity. Instead, it appears that the quadratic or linear-quadratic is a reasonable way of approximating the shape of the damage function.

\section{General conclusion on impact studies}

An additional warning is that the impact estimates are generally not comprehensive. They often cover key sectors such as agriculture, sea-level rise, energy, and forestry. Most do not include many non-market impacts, and the quantifications of non-market impacts that do exist are generally just guesses. As examples, estimates of the losses from ecosystems or damages from melting permafrost are omitted or unreliable. This point suggests that the figures examined here are likely to be underestimates of true damages.

As a final conclusion, we emphasize the limited nature of work on impacts. There are hundreds, perhaps thousands, of impact studies in different areas such as health, agriculture, energy, ecosystems, and coastal structures. However, very few are comprehensive both in sectors and regions.

Moreover, few organizations have the resources to integrate different studies to prepare the comprehensive estimates that are needed for use in economic-climate modeling. Virtually all the work on impacts has been performed by small groups of scholars. By comparison with studies in other parts of the climate-change nexus (such as monitoring or climate modeling), comprehensive impact studies are almost an afterthought in the study of climate change. Yet they are critical in estimates of policy instruments, such as the social cost of carbon, or the appropriate emissions, concentrations, or temperature targets. Concentrated independent scholarly work on impacts is critically needed. 


\section{Appendices}

A. Supplemental tables

B. Source of $25 \%$ additional damages from Nordhaus and Sztorc (2013) 


\section{Appendix A.}

\begin{tabular}{|c|c|c|c|}
\hline Study & JSTOR & EconLit & $\begin{array}{l}\text { Google } \\
\text { Scholar }\end{array}$ \\
\hline $\begin{array}{l}\text { Managing the Global Commons: The Economics of } \\
\text { Climate Change (Nordhaus, 1994) }\end{array}$ & & X & X \\
\hline \multicolumn{4}{|l|}{ Expert Opinion on Climate Change (Nordhaus, 1994) } \\
\hline $\begin{array}{l}\text { Valuing Climate Change-The Economics of the } \\
\text { Greenhouse (Fankhauser, 1995) }\end{array}$ & & X & X \\
\hline $\begin{array}{l}\text { The Damage Costs of Climate Change Toward More } \\
\text { Comprehensive Calculations (Tol, 1995) }\end{array}$ & & X & X \\
\hline $\begin{array}{l}\text { A regional dynamic general-equilibrium model of } \\
\text { alternative climate-change strategies (Nordhaus and } \\
\text { Yang, 1996) }\end{array}$ & $\mathrm{X}$ & $\mathrm{X}$ & $\mathrm{X}$ \\
\hline $\begin{array}{l}\text { PAGE95-An Updated Valuation of the Impacts of } \\
\text { Global Warming (Plambeck and Hope, 1996) }\end{array}$ & & & X \\
\hline $\begin{array}{l}\text { Country-Specific Market Impacts of Climate Change } \\
\text { (Mendelsohn, Schlesinger and Williams, 2000) }\end{array}$ & & & X \\
\hline $\begin{array}{l}\text { Warming the World: Economic Models of Global } \\
\text { Warming (Nordhaus and Boyer, 2000) }\end{array}$ & & $\mathrm{X}$ & $\mathrm{X}$ \\
\hline $\begin{array}{l}\text { Estimates of the Damage Costs of Climate Change } \\
\text { (Tol, 2002) }\end{array}$ & & $\mathrm{X}$ & $\mathrm{X}$ \\
\hline $\begin{array}{l}\text { The Amenity Value of the Climate: The Household } \\
\text { Production Function Approach (Maddison, 2003) }\end{array}$ & & $\mathrm{X}$ & $\mathrm{X}$ \\
\hline $\begin{array}{l}\text { Climate and Happiness (Rehdanz and Maddison, } \\
\text { 2005) }\end{array}$ & & $\mathrm{X}$ & $\mathrm{X}$ \\
\hline $\begin{array}{l}\text { The Marginal Impact of CO2 from PAGE2002: An } \\
\text { Integrated Assessment Model Incorporating the } \\
\text { IPCC's Five Reasons for Concern (Hope, 2006) }\end{array}$ & & & $\mathrm{X}$ \\
\hline $\begin{array}{l}\text { Geography and Macroeconomics: New Data and New } \\
\text { Findings (Nordhaus, 2006) }\end{array}$ & X & & $\mathrm{X}$ \\
\hline $\begin{array}{l}\text { A Question of Balance-Weighing the Options on } \\
\text { Global Warming Policies (Nordhaus, 2008) }\end{array}$ & & & X \\
\hline $\begin{array}{l}\text { The Impact of Climate on Life Satisfaction (Maddison } \\
\text { and Rehdanz, 2011) }\end{array}$ & & $\mathrm{X}$ & $\mathrm{X}$ \\
\hline
\end{tabular}




\begin{tabular}{|c|c|c|}
\hline $\begin{array}{l}\text { Assessing the Economic Impacts of Climate Change } \\
\text { (Bosello et al., 2012) }\end{array}$ & $\mathrm{X}$ & $\mathrm{X}$ \\
\hline $\begin{array}{l}\text { Climate Change and Economic Growth: Impacts and } \\
\text { Interactions (Roson and van der Mensbrugghe, 2012) }\end{array}$ & $\mathrm{X}$ & $\mathrm{X}$ \\
\hline $\begin{array}{l}\text { The Climate Casino: Risk, Uncertainty, and Economics } \\
\text { for a Warming World (Nordhaus, 2013) }\end{array}$ & $\mathrm{X}$ & $\mathrm{X}$ \\
\hline Total 2 & 12 & 17 \\
\hline
\end{tabular}

Table A-1. Success rate of search engines

The above table shows with an " $\mathrm{X}$ " if the given platform turned up the given study in one of the three search engines used. This search examined only the studies used in Tol (2014). A platform was given an " $X$ " if it had the study in its database, regardless of whether it was returned as a result from our search string. The number of studies turned up with the search string was smaller than the number shown here, so the number here is the maximum that could be included with an ideal set of search strings. 


\begin{tabular}{|c|c|}
\hline \multicolumn{2}{|c|}{ Category } \\
\hline 0 & Not related to our research \\
\hline $1 \mathrm{~g}$ & $\begin{array}{l}\text { Ideal (new data for damages to all } \\
\text { sectors globally) }\end{array}$ \\
\hline 1g-tweak & Just a minor variation of a $1 \mathrm{~g}$ paper \\
\hline 2 & $\begin{array}{l}\text { Damages globally but for not all sectors } \\
\text { (e.g. just agriculture) }\end{array}$ \\
\hline 3 & $\begin{array}{l}\text { Damages for all sectors but just for one } \\
\text { country }\end{array}$ \\
\hline 4 & $\begin{array}{l}\text { Damages but not global and not all } \\
\text { sectors }\end{array}$ \\
\hline 5 & Literature review of damages \\
\hline
\end{tabular}

\section{Confidence}

\begin{tabular}{l}
\hline High \\
Med \\
Low \\
\hline
\end{tabular}

Table A-2. Rating system for abstracts

Rating system used during the SRS to evaluate relevance of study to our research and researcher's confidence that this rating is accurate. This was used to determine whether an abstract that was identified (about 1700 total) should be included in the articles to be read (24 total). 
Beginning of Table A-3.

Note: Studies or entries which have errors are cannot be replicated are marked as follows: (E09) for error in 2009 article; (E14) for error in 2014 article; (NR) for not replicable; (Y) for confirmed

Further note on temperature: We have based the temperature increase from the global average in 1920-1940. The increase from that base is calculated to be $0.64,0.730,0.72$, $0.82{ }^{\circ} \mathrm{C}$ above the base for 2000, 2005, 2010, and 2015 (where we use five-year moving averages when possible).

\section{Estimates from Tol surveys}

The following studies were included in Tol (2009)

Nordhaus a, 1994a (Y)

The impact presented in Tol (2014) is $-1.3 \%$ of global output for a three-degree C temperature increase. This has been rounded from the author's finding of $-1.33 \%$ and is generally correct. This paper uses $-1.33 \%$ for accuracy.

Nordhaus b, 1994 (E09, E14)

(i) The impact presented in Tol (2014) is $-3.6 \%$ for a three-degree C temperature increase and is the mean estimate of the likelihood of high consequence events presented in scenario A of the study. (ii) Tol excluded scenarios B and C from his survey; these scenarios report significantly higher impacts and were excluded from Tol without discussion. We also include scenario B in our analysis as 1994b-ii. This is an example of where the Tol survey selected only one of multiple scenarios, and in this case was the one with the lowest impact.

Fankhauser, 1995 (Y)

The estimate used is in line with the authors' findings.

Tol, 1995 (Y)

The figure Tol cites in 2014 is correct. It has, however, been incorrectly cited elsewhere. Fankhauser (1995) cites it as -1.5\% GNP for a 3-degree $\mathrm{C}$ temperature rise while Mendelsohn (2000) cites it as $-1.5 \%$ GNP for a 2.5-degree $C$ rise. Tol's actual study shows an impact of $-1.9 \%$ on global GNP and an impact of $-1.5 \%$ of USA GNP for a CO2 doubling, which is 2.5 degrees in his model. Global figures have been used in the present study.

Nordhaus and Yang, 1996 (Y)

In the original study by Nordhaus and Yang the impacts of increased temperature on output were reported in regional figures rather than global. The global estimate provided in Tol (2014) is confirmed using weights for 2100 and impact coefficients as shown in Table 2 of Nordhaus and Yang.

Plambeck and Hope, 1996 (E09, E14) 
This study relies on the PAGE95 model. No methods were provided by Tol, and no estimates of damages appear in the article. We cannot find any source for the impact, and the PAGE95 is not being supported by its author. Therefore, we have no estimate for this study.

Mendelsohn, Morrison, Schlesinger, and Andronova or MMSA (2000) and Mendelsohn, Schlesinger, and Williams or MSW (2000) (E09, E14)

Tol (2009) and Tol (2014) differ in the study referenced with no explanation for the difference. These two studies use similar methodologies but have different underlying models and results. None of the results in either of the original studies corresponds to the results reported by Tol (2009) or (2014). MMSA reports 3 temperature increases and four results. We report the two higher temperature changes. MSW reports results for several models, and we report the model average, which are all for a $2.2^{\circ} \mathrm{C}$ increase. The results are (i) a benefit of $0.03 \%$ for experimental impacts functions and (ii) $0.07 \%$ for cross-sectional impacts functions. MMSA reports 3 temperature increases and four results. We report the two higher temperature changes. The average results for (iii) are 2 ${ }^{\circ} \mathrm{C}$ shows a benefit of $0.08 \%$ and while (iv) the result for $3.5^{\circ} \mathrm{C}$ is a benefit of $0.01 \%$.

Nordhaus and Boyer, 2000 (Y)

Tol (2014) reports the output-weighted figure of climate change impacts for a 2.5-degree $\mathrm{C}$ temperature increase of $-1.5 \%$ of global output, which is correct. The original study reports another impact figure that is population-weighted, and is $-1.88 \%$. In the present study, we also used output weighted figures and note where there are weighting-related differences.

Tol, $2002(Y)$

The estimate used is in line with the authors' findings.

Maddison, 2003 (NR)

The results could not be replicated because the method was not stated. It's unclear how Tol got damages of $-0.1 \%$ of global output. Maddison assumed a household production function and ran a regression to find the increase in costs of several commodities due to temperature and precipitation changes, controlling for several potentially confounding variables. He then estimated for the change in cost of living index for 88 countries due to a 2.5-degree $\mathrm{C}$ temperature increase. Changes in temperature and precipitation due to a 2.5-degree $C$ temperature increase were estimated using the United Kingdom Meteorological Office's GCM. It is not stated whether the increase is relative to contemporaneous or pre-industrial, but the logic is clear that it is for contemporaneous (roughly 2000), so we have added $0.6^{\circ} \mathrm{C}$ to make the figures comparable with other studies. We take IMF data on country-level 2010 GDP using market exchange rates. We calculate weighting factors as the country's share of output relative to all the countries included in the study. This weighting factor is multiplied by the study's cost of living index change figure to find country-specific damages. These are summed to find global damages in 2100 due to 2.5 degree $\mathrm{C}$ temperature increase. Note that the results exclude China and the Russian Federation. 


\section{Rehdanz and Maddison, 2005 (O, Y)}

The authors estimate the extent to which changes in temperature and precipitation affect happiness using panel data on 67 countries. They calculate the amount GDP would need to increase (decrease) to offset the change in happiness due to temperature and precipitation changes for two 30-year time periods. They use the first regression model to get GDP impact, which used mean temperature in the hottest and coldest month and mean precipitation in the wettest and driest month. They use that climate coefficient to get the GDP increase (decrease) needed to maintain happiness at its current level given the predicted changes in temperature and precipitation for two time intervals of 30 years each. It is important to note that the authors do not compute damages for a specific average surface air temperature increase for these time intervals, but rather compute it for an average rise in the mean warmest and coolest months. Tol, according to his own account, added up the numbers by country.

The authors present two results, (i) for 2069and (ii) for 2039. The data are averaged from $14 \mathrm{GCMs}$ and scaled to a projected mean global temperature increase of 0.620 degrees $C$ and 1.024 degrees $C$ for each of the two time intervals ending in years 2039 and 2069, respectively. The deviations are from the average of $1961-90$. These are $0.24{ }^{\circ} \mathrm{C}$ above preindustrial, so we have added this number to the temperature change.

We have used IMF 2010 data on GDP using market exchange rates and scaled this up to the relevant years using assumed FUND regional growth rates. Because the authors compute losses in terms of 1995 per capita dollar amounts, we use 2010 per capita GDP figures to find an implied percent decrease after adjusting for inflation. This is then applied to the country GDP and multiplied by the country-weighting factor, which is its relative output to global output of countries included in the study. These damages are then summed to reach the final global damages in four instances, with two distinct time intervals and two climate conditions. We report damage estimates that include damages from both temperature and precipitation. It is noteworthy that our results show that damages are a smaller share of global GDP in 2069 than in 2039, and that damages are higher assuming that they are only due to temperature increases rather than both changes in temperature and precipitation. 
Hope, 2006 (E09, E14)

This study uses the PAGE2002 model. The study does not report an impact value. The 2010 Interagency Working Group (p. 9) provides an estimate based on model runs, which calculates an impact of $-1.4 \%$ at a $3{ }^{\circ} \mathrm{C}$ warming. We cannot replicate this number and find an impact of $-1.1 \%$ at a $3{ }^{\circ} \mathrm{C}$ warming. The estimates reported in Tol (2009) are $+0.9 \%$ or $-0.9 \%$ in Tol (2014). On Tol estimates, note that the first estimate had a benefit, while the second had a cost. They are both wrong and cannot be replicated.

The number quoted in the present paper was derived by the authors as follows: Hope provided 10,000 runs of the model. We fitted a quadratic regression and used the prediction of the model at $2.5^{\circ} \mathrm{C}$ warming.

Nordhaus, 2006 (E09, E14)

This study provides impacts on global output of a temperature increase with and without mid-continental drying and with three different weightings: area, population and output. Tol $(2009,2014)$ reports $(i)$, which is the estimate without continental drying and output-weighted. This was clearly not preferred. The preferred estimate (ii) clearly stated in Nordhaus (2006) is output-weighted, but with continental drying, bringing the estimate up to 1.05 percent of global income. Tol also indicated that one of the damage estimates is calibrated to a 2.5-degree $\mathrm{C}$ temperature increase, whereas it is actually for 3-degrees C.

The following studies were not included in Tol (2009) but were included in Tol (2014).

Nordhaus, 2008 (Y)

The estimate provided by Tol (2014) of -2.5 percent of global output deviates only slightly from the actual figure of -2.6 percent. This was incorrectly reported as included in Tol (2009) in Table 1 of Tol (2014).

Maddison and Rehdanz, 2011 (NR)

It is unclear how Tol estimated damages of - 11.5 percent of global output. This study is very similar to Rehdanz and Maddison (2005) in approach and scope. A key point to note is that in this study the authors measure WTA for losses and WTP for gains. By aggregating panel data for 79 countries on happiness scores taken from the World Value Survey and combining that with climate data they aim to approximate the impact climate can have on life satisfaction. Climate is coded as 'degree-months', which is the aggregate monthly difference between the measured climate from a temperature of $65^{\circ} \mathrm{F}\left(18.3^{\circ} \mathrm{C}\right)$. Damages, or compensating surplus as it is termed in the study, are found by calculating the difference in satisfaction that would be required to account for the change in degreemonths from climate change. The authors use Hadley CM3's SRES A2 climate scenario, which predicts a 4-degree $C$ temperature increase above pre-industrial levels by 2070 2099 (Betts et al., 2011). We scaled global income to the year 2085, which is the middle of the range provided by the authors. It appears Tol has incorrectly used a median temperature result from the A1Fl scenario. To find aggregate damages we aggregated the 
product of the percentage change in welfare reported by the authors and individual country output weighting factors.

Bosello et al., 2012 (Y)

The study is a CGE analysis of 7 sectors and 14 regions. The results in Tol are correctly reported. The sources of the impacts by sectors are not clearly described.

Roson and van der Mensbrugghe, 2012 (E09)

Tol's estimates are (i) for 2050 and (ii) 2100. Both are wrong. The damage estimate is from the following: "According to our preliminary estimates, at the global level, the most serious consequence from climate change will be changes to labor productivity that would induce $84 \%$ of the global damage in 2050 (-1.8\% of global GDP) and $76 \%$ in 2100 (-4.6\% of global GDP)." This implies a total impact of $-2.14 \%$ and $-6.05 \%$ for the two years. The temperature increase according to Figure 4 and correspondence with the authors are 2.3 and $4.8{ }^{\circ} \mathrm{C}$ increase over 2000 . We translate these into 3.0 and $5.5^{\circ} \mathrm{C}$ relative to $1920-40$ find a $-1.8 \%$ and $-4.6 \%$ impact on global output due to temperature increases of 3.0 and 5.5 degrees C, respectively. According to Tol, Robert Kopp subsequently acquired the original data from Roson, and found that the original version was correct after all.

Nordhaus, 2013 (E09)

This study relies on the DICE-2013R model for its estimates. The cited number in Tol (2014) is incorrect. A calculation from the model finds that the damage/net output ratio at $2.9^{\circ} \mathrm{C}$ is $-2.3 \%$ of global output, instead of $-2.0 \%$ as reported in Tol (2014). Tol reports that he read the results for this and other studies from the graphs.

\section{Studies added for from systematic research synthesis}

See Table 2.

\section{Studies added for statistical analysis}

We have added three studies for our statistical analysis. The estimates for the FUND and WITCH model are from the MUP study (Gillingham 2015). They take the estimated damage/output ratio for 2080 - 2100 that most closely approximates the temperature increase.

The estimates for PAGE09 were made in the same way as for PAGE2002 above, except that we have taken three temperature increases. Each set of estimates is taken to be reliable and the three are given a total weight of 1 .

\section{Table A-3. Explanations of estimates of impacts for studies}




\begin{tabular}{|c|c|}
\hline Region & Countries \\
\hline USA & United States of America \\
\hline CAN & Canada \\
\hline WEU & $\begin{array}{l}\text { Andorra, Austria, Belgium, Cyprus, Denmark, Finland, France, Germany, Greece, Iceland, } \\
\text { Ireland, Italy, Liechtenstein, Luxembourg, Malta, Monaco, Netherlands, Norway, Portugal, } \\
\text { San Marino, Spain, Sweden, Switzerland, United Kingdom }\end{array}$ \\
\hline JPK & Japan, South Korea \\
\hline ANZ & Australia, New Zealand \\
\hline CEE & $\begin{array}{l}\text { Albania, Bosnia and Herzegovina, Bulgaria, Croatia, Czech Republic, Hungary, Kosovo, } \\
\text { Macedonia, Montenegro, Poland, Romania, Serbia, Slovak Republic, Slovenia }\end{array}$ \\
\hline FSU & $\begin{array}{l}\text { Armenia, Azerbaijan, Belarus, Estonia, Georgia, Kazakhstan, Kyrgyz Republic, Latvia, } \\
\text { Lithuania, Moldova, Russian Federation, Tajikistan, Turkmenistan, Ukraine, Uzbekistan }\end{array}$ \\
\hline MDE & $\begin{array}{l}\text { Bahrain, Iran, Iraq, Israel, Jordan, Kuwait, Lebanon, Oman, Qatar, Saudi Arabia, Syria, Turkey, } \\
\text { United Arab Emirates, West Bank and Gaza, Yemen, Rep. }\end{array}$ \\
\hline CAM & Belize, Costa Rica, El Salvador, Guatemala, Honduras, Mexico, Nicaragua, Panama \\
\hline SAM & $\begin{array}{l}\text { Argentina, Bolivia, Brazil, Chile, Colombia, Ecuador, Guyana, Paraguay, Peru, Suriname, } \\
\text { Uruguay, Venezuela }\end{array}$ \\
\hline SAS & Afghanistan, Bangladesh, Bhutan, India, Nepal, Pakistan, Sri Lanka \\
\hline SEA & $\begin{array}{l}\text { Brunei Darussalam, Cambodia, Indonesia, Lao PDR, Malaysia, Myanmar, Papua New Guinea, } \\
\text { Philippines, Singapore, Thailand, Timor-Leste, Vietnam }\end{array}$ \\
\hline CHI & China, Hong Kong, Korea, Dem. People's Rep., Macao SAR, China, Mongolia \\
\hline NAF & Algeria, Egypt, Libya, Morocco, Tunisia \\
\hline SSA & $\begin{array}{l}\text { Angola, Benin, Botswana, Burkina Faso, Burundi, Cabo Verde, Cameroon, Central African } \\
\text { Republic, Chad, Congo, Congo, Rep., Djibouti, Equatorial Guinea, Eritrea, Ethiopia, Gabon, } \\
\text { Gambia, The, Ghana, Guinea, Guinea-Bissau, Ivory Coast, Kenya, Lesotho, Liberia, } \\
\text { Madagascar, Malawi, Mali, Mauritania, Mozambique, Namibia, Niger, Nigeria, Rwanda, } \\
\text { Senegal, Sierra Leone, Somalia, South Africa, South Sudan, Sudan, Swaziland, Tanzania, Togo, } \\
\text { Uganda, Zambia, Zimbabwe }\end{array}$ \\
\hline SIS & $\begin{array}{l}\text { Antigua and Barbuda, Aruba, Bahamas, Barbados, Bermuda, Comoros, Cuba, Dominica, } \\
\text { Dominican Republic, Fiji, French Polynesia, Grenada, Haiti, Jamaica, Kiribati, Maldives, } \\
\text { Marshall Islands, Mauritius, Micronesia, Fed. Sts., New Caledonia, Palau, Puerto Rico, Samoa, } \\
\text { Sao Tome and Principe, Seychelles, Solomon Islands, St. Kitts and Nevis, St. Vincent and the } \\
\text { Grenadines, Tonga, Trinidad and Tobago, Tuvalu, Vanuatu, Virgin Islands (U.S.) }\end{array}$ \\
\hline
\end{tabular}

\section{Table A-4. List of countries per region as coded in this study}

Regions are taken from the FUND model and countries from IMF databases. [The source from FUND was from the Technical Table available in 2016 but no longer available. IMF data from data.imf.org.] 


\begin{tabular}{|c|c|c|c|c|c|c|c|c|}
\hline & $\begin{array}{l}\text { Maddison } \\
2003 \\
(2010)\end{array}$ & $\begin{array}{l}\text { Plambeck } \\
\text { and Hope } \\
1996 \text { and } \\
\text { Maddison } \\
2003 \\
(2100)\end{array}$ & $\begin{array}{l}\text { Rehdanz } \\
\text { and } \\
\text { Maddison } \\
2005 \\
(2010)\end{array}$ & $\begin{array}{l}\text { Rehdanz } \\
\text { and } \\
\text { Maddison } \\
2005 \\
(2069)\end{array}$ & $\begin{array}{l}\text { Maddison } \\
\text { and } \\
\text { Rehdanz } \\
2011 \\
(2010)\end{array}$ & $\begin{array}{l}\text { Maddison } \\
\text { and } \\
\text { Rehdanz } \\
2011 \\
(2085)\end{array}$ & $\begin{array}{l}\text { Kemfert } \\
2001 \\
(2010)\end{array}$ & $\begin{array}{l}\text { Kemfert } \\
2001 \\
(2050)\end{array}$ \\
\hline USA & $28 \%$ & $16 \%$ & $26 \%$ & $18 \%$ & $25 \%$ & $13 \%$ & $23 \%$ & $17 \%$ \\
\hline CAN & $3 \%$ & $2 \%$ & $3 \%$ & $2 \%$ & $3 \%$ & $1 \%$ & $2 \%$ & $2 \%$ \\
\hline WEU & $31 \%$ & $17 \%$ & $29 \%$ & $19 \%$ & $24 \%$ & $13 \%$ & $26 \%$ & $19 \%$ \\
\hline JPK & $12 \%$ & $8 \%$ & $12 \%$ & $9 \%$ & $11 \%$ & $7 \%$ & $10 \%$ & $8 \%$ \\
\hline ANZ & $3 \%$ & $2 \%$ & $2 \%$ & $2 \%$ & $2 \%$ & $1 \%$ & $2 \%$ & $2 \%$ \\
\hline CEE & $2 \%$ & $2 \%$ & $2 \%$ & $3 \%$ & $2 \%$ & $2 \%$ & $2 \%$ & $3 \%$ \\
\hline FSU & $0 \%$ & $0 \%$ & $1 \%$ & $1 \%$ & $3 \%$ & $4 \%$ & $3 \%$ & $4 \%$ \\
\hline MDE & $3 \%$ & $8 \%$ & $2 \%$ & $4 \%$ & $3 \%$ & $8 \%$ & $4 \%$ & $7 \%$ \\
\hline CAM & $2 \%$ & $5 \%$ & $2 \%$ & $3 \%$ & $2 \%$ & $3 \%$ & $2 \%$ & $2 \%$ \\
\hline SAM & $7 \%$ & $15 \%$ & $6 \%$ & $10 \%$ & $6 \%$ & $10 \%$ & $6 \%$ & $8 \%$ \\
\hline SAS & $4 \%$ & $10 \%$ & $3 \%$ & $6 \%$ & $3 \%$ & $6 \%$ & $3 \%$ & $5 \%$ \\
\hline SEA & $3 \%$ & $7 \%$ & $0 \%$ & $1 \%$ & $3 \%$ & $6 \%$ & $3 \%$ & $4 \%$ \\
\hline CHI & $0 \%$ & $1 \%$ & $11 \%$ & $20 \%$ & $10 \%$ & $20 \%$ & $10 \%$ & $14 \%$ \\
\hline NAF & $1 \%$ & $2 \%$ & $0 \%$ & $0 \%$ & $1 \%$ & $2 \%$ & $1 \%$ & $2 \%$ \\
\hline SSA & $1 \%$ & $4 \%$ & $1 \%$ & $3 \%$ & $1 \%$ & $4 \%$ & $2 \%$ & $4 \%$ \\
\hline SIS & $0 \%$ & $0 \%$ & $0 \%$ & $0 \%$ & $0 \%$ & $0 \%$ & $0 \%$ & $0 \%$ \\
\hline
\end{tabular}

Table A-5. Output shares used to estimate global averages

Output shares per region by study and year using IMF data and FUND growth estimates. These percentages the regional share of global output. 


\begin{tabular}{|c|c|c|c|c|c|}
\hline Study & Year & $\begin{array}{l}\text { Temper- } \\
\text { ature }\end{array}$ & Impact & Weight & Reason \\
\hline Cline & 1992 & 2.5 & $(1.10)$ & 0.90 & Careful and comprehensive \\
\hline Cline & 1992 & 10 & $(6.00)$ & 0.10 & Highly speculative \\
\hline Nordhaus a & 1994 & 3 & $(1.33)$ & 0.00 & Outdated \\
\hline Nordhaus b & 1994 & 3 & $(3.60)$ & 0.50 & Unique expert survey \\
\hline Nordhaus b & 1994 & 6 & $(10.40)$ & 0.50 & Unique expert survey \\
\hline Fankhauser & 1995 & 2.5 & $(1.40)$ & 1.00 & Important survey \\
\hline Tol & 1995 & 2.5 & $(1.90)$ & 0.10 & Superceded \\
\hline Nordhaus and Yang & 1996 & 2.5 & $(1.70)$ & 0.10 & Superceded \\
\hline Pambeck and Hope & 1996 & 2.2 & & 0.00 & Can not confirm estimate \\
\hline $\begin{array}{l}\text { Mendelsohn, Schlesinger, and } \\
\text { Williams }\end{array}$ & 2000 & 2.2 & 0.03 & 0.10 & Superceded \\
\hline $\begin{array}{l}\text { Mendelsohn, Schlesinger, and } \\
\text { Williams }\end{array}$ & 2000 & 2.2 & 0.07 & 0.10 & Superceded \\
\hline $\begin{array}{l}\text { Mendelsohn, Morrison, } \\
\text { Schlesinger, and Andronova }\end{array}$ & 2000 & 2 & 0.08 & 0.10 & Superceded \\
\hline Mendelsohn, Morrison, & & & & & \\
\hline Schlesinger, and Andronova & 2000 & 3.5 & 0.01 & 0.10 & Superceded \\
\hline Nordhaus and Boyer & 2000 & 2.5 & $(1.50)$ & 1.00 & Independent estimates \\
\hline Tol & 2002 & 1 & 2.30 & 0.10 & Superceded \\
\hline Maddison & 2003 & 3.1 & $(2.22)$ & 0.10 & Poor methods \\
\hline Rehdanz and Maddison & 2005 & 1.24 & $(0.32)$ & 0.10 & Poor methods \\
\hline Rehdanz and Maddison & 2005 & 0.84 & $(0.32)$ & 0.10 & Poor methods \\
\hline Hope & 2006 & 4.085 & $(3.04)$ & 0.25 & Early study \\
\hline Nordhaus & 2006 & 3 & $(1.05)$ & 1.00 & Econometric, preferred \\
\hline Nordhaus & 2008 & 3 & $(2.49)$ & 0.25 & Update \\
\hline Nordhaus & 2010 & 3.4 & $(2.80)$ & 0.25 & Update \\
\hline Maddison and Rehdanz & 2011 & 4 & $(17.80)$ & 0.10 & Poor methods \\
\hline Bosello et al. & 2012 & 1.92 & $(0.50)$ & 1.00 & Excellent approach \\
\hline $\begin{array}{l}\text { Roson and van der } \\
\text { Mensbrugghe } \\
\text { Roson and van der }\end{array}$ & 2012 & 3.1 & $(2.14)$ & 0.10 & Poor methods \\
\hline Mensbrugghe & 2012 & 5.5 & $(6.05)$ & 0.10 & Poor methods \\
\hline Dellink & 2012 & 2.5 & $(1.10)$ & 1.00 & Excellent approach \\
\hline Kemfert & 2012 & 0.25 & $(0.17)$ & 0.10 & Derivative damage estimates \\
\hline Hambel & 2012 & 1 & $(0.30)$ & 0.10 & Poor methods \\
\hline Nordhaus & 2013 & 3 & $(2.25)$ & 0.00 & Incorrect survey \\
\hline FUND & 2015 & 2 & 0.20 & 0.30 & Runs from MUP study \\
\hline FUND & 2015 & 3 & $(0.17)$ & 0.40 & Runs from MUP study \\
\hline FUND & 2015 & 4 & $(0.85)$ & 0.30 & Runs from MUP study \\
\hline WITCH & 2015 & 2 & $(1.84)$ & 0.30 & Runs from MUP study \\
\hline WITCH & 2015 & 3 & $(3.72)$ & 0.40 & Runs from MUP study \\
\hline WITCH & 2015 & 4 & $(6.25)$ & 0.30 & Runs from MUP study \\
\hline PAGE09 & 2017 & 2 & $(0.72)$ & 0.30 & From Hope data \\
\hline PAGE09 & 2017 & 4 & $(2.90)$ & 0.40 & From Hope data \\
\hline PAGE09 & 2017 & 6 & $(6.51)$ & 0.30 & From Hope data \\
\hline
\end{tabular}

Table A-6. Weights, results, and reason for weights, by study and yearx 
This table shows the weight for each estimate included in the statistical analysis. Note that the sum of the weights for data points of a study is that study's weight. For example, at the bottom of the table, FUND 2015 has three data points whose weights sum to 1 . The weights were determined by the authors. ${ }^{\mathrm{xi}}$

\begin{tabular}{|c|c|c|c|c|c|c|c|c|c|c|c|c|c|c|c|}
\hline Weights & Method & Specif & $\begin{array}{c}\mathrm{T} \\
\text { spec }\end{array}$ & $\begin{array}{c}\mathrm{T} \\
\text { limit }\end{array}$ & $c(1)$ & se $c(1)$ & $\mathrm{tc}(1)$ & $c(2)$ & se $c(2)$ & $\mathrm{tc}(2)$ & N & R2bar & $\begin{array}{l}\text { Stand } \\
\text { Err Eq }\end{array}$ & $\begin{array}{c}\text { Pred at } \\
3^{\circ} \mathrm{C}\end{array}$ & $\begin{array}{l}\text { Pred at } \\
6^{\circ} \mathrm{C}\end{array}$ \\
\hline Unweighted & OLS & Quad & $\mathrm{T}>=$ & - & $(0.13)$ & 0.03 & (4.82) & & & & 38 & 0.12 & 3.25 & (1.15) & $(4.60)$ \\
\hline Unweighted & OLS & Quad & $\mathrm{T}>=$ & 1 & $(0.13)$ & 0.03 & $(4.82)$ & & & & 38 & 0.12 & 3.25 & (1.15) & $(4.60)$ \\
\hline Unweighted & OLS & Quad & $\mathrm{T}>=$ & 2 & $(0.13)$ & 0.03 & $(4.68)$ & & & & 36 & 0.10 & 3.34 & (1.15) & $(4.60)$ \\
\hline Unweighted & OLS & Quad & $\mathrm{T}>=$ & 3 & $(0.13)$ & 0.03 & $(4.52)$ & & & & 33 & 0.04 & 3.47 & (1.15) & (4.61) \\
\hline Unweighted & OLS & Quad & $\mathrm{T}>=$ & 4 & $(0.13)$ & 0.04 & (3.43) & & & & 20 & $(0.14)$ & 4.46 & $(1.14)$ & (4.56) \\
\hline Unweighted & Median & Quad & $T>=$ & - & $(0.18)$ & 0.05 & (3.33) & & & & 38 & 0.19 & 3.43 & (1.64) & (6.55) \\
\hline Unweighted & Median & Quad & $T>=$ & 1 & $(0.18)$ & 0.05 & (3.33) & & & & 38 & 0.19 & 3.43 & (1.64) & (6.55) \\
\hline Unweighted & Median & Quad & $\mathrm{T}>=$ & 2 & $(0.18)$ & 0.06 & $(3.08)$ & & & & 36 & 0.17 & 3.52 & $(1.64)$ & (6.55) \\
\hline Unweighted & Median & Quad & $T>=$ & 3 & $(0.18)$ & 0.06 & (2.96) & & & & 33 & 0.13 & 3.66 & (1.64) & (6.55) \\
\hline Unweighted & Median & Quad & $T>=$ & 4 & $(0.18)$ & 0.11 & $(1.60)$ & & & & 20 & $(0.01)$ & 4.72 & $(1.64)$ & (6.55) \\
\hline Weighted & OLS & Quad & $T>=$ & - & $(0.21)$ & 0.02 & (11.47) & & & & 38 & 0.62 & 1.69 & (1.92) & (7.68) \\
\hline Weighted & OLS & Quad & $\mathrm{T}>=$ & 1 & $(0.21)$ & 0.02 & (11.47) & & & & 38 & 0.62 & 1.69 & (1.92) & (7.68) \\
\hline Weighted & OLS & Quad & $\mathrm{T}>=$ & 2 & $(0.21)$ & 0.02 & (11.16) & & & & 36 & 0.62 & 1.67 & $(1.92)$ & (7.68) \\
\hline Weighted & OLS & Quad & $T>=$ & 3 & $(0.21)$ & 0.02 & (10.70) & & & & 33 & 0.62 & 1.64 & (1.92) & (7.68) \\
\hline Weighted & OLS & Quad & $\mathrm{T}>=$ & 4 & $(0.22)$ & 0.03 & (7.67) & & & & 20 & 0.54 & 2.68 & (1.95) & (7.79) \\
\hline Weighted & Med & Quad & $\mathrm{T}>=$ & - & $(0.18)$ & 0.04 & (5.11) & & & & 38 & 0.27 & 1.75 & (1.64) & (6.55) \\
\hline Weighted & Med & Quad & $\mathrm{T}>=$ & 1 & $(0.18)$ & 0.04 & (5.11) & & & & 38 & 0.27 & 1.75 & (1.64) & (6.55) \\
\hline Weighted & Med & Quad & $T>=$ & 2 & $(0.18)$ & 0.04 & (4.85) & & & & 36 & 0.27 & 1.74 & (1.64) & (6.55) \\
\hline Weighted & Med & Quad & $\mathrm{T}>=$ & 3 & $(0.18)$ & 0.04 & $(4.56)$ & & & & 33 & 0.26 & 1.70 & (1.64) & (6.55) \\
\hline Weighted & Med & Quad & $T>=$ & 4 & $(0.18)$ & 0.10 & (1.91) & & & & 20 & 0.16 & 2.78 & $(1.64)$ & (6.55) \\
\hline Unweighted & OLS & Quad & $\mathrm{T}<=$ & 3 & 0.26 & 0.52 & 0.50 & & & & 5 & 0.01 & 1.15 & 2.35 & 9.38 \\
\hline Unweighted & OLS & Quad & $\mathrm{T}<=$ & 4 & $(0.18)$ & 0.04 & (4.12) & & & & 18 & 0.32 & 0.82 & $(1.60)$ & (6.40) \\
\hline Unweighted & OLS & Quad & $\mathrm{T}<=$ & 5 & $(0.19)$ & 0.03 & $(7.20)$ & & & & 30 & 0.35 & 1.01 & $(1.71)$ & (6.83) \\
\hline Unweighted & OLS & Quad & $\mathrm{T}<=$ & 6 & $(0.27)$ & 0.05 & (5.35) & & & & 35 & 0.28 & 2.70 & $(2.47)$ & (9.88) \\
\hline Unweighted & OLS & Quad & $\mathrm{T}<=$ & 7 & $(0.26)$ & 0.04 & (5.79) & & & & 36 & 0.30 & 2.68 & $(2.30)$ & (9.21) \\
\hline Unweighted & OLS & Quad & $\mathrm{T}<=$ & 8 & $(0.26)$ & 0.04 & (7.05) & & & & 37 & 0.41 & 2.65 & (2.38) & (9.52) \\
\hline Unweighted & OLS & Quad & $\mathrm{T}<=$ & 3 & $(0.21)$ & NA & NA & & & & 5 & $(0.05)$ & 1.26 & (1.90) & (7.59) \\
\hline Unweighted & OLS & Quad & $\mathrm{T}<=$ & 4 & $(0.19)$ & 0.07 & $(2.87)$ & & & & 18 & 0.26 & 0.83 & (1.73) & (6.93) \\
\hline Unweighted & OLS & Quad & $\mathrm{T}<=$ & 5 & $(0.22)$ & 0.04 & (5.51) & & & & 30 & 0.27 & 1.04 & $(2.00)$ & (8.02) \\
\hline Unweighted & OLS & Quad & $\mathrm{T}<=$ & 6 & $(0.19)$ & 0.04 & (5.34) & & & & 35 & 0.22 & 2.79 & $(1.73)$ & (6.93) \\
\hline Unweighted & OLS & Quad & $\mathrm{T}<=$ & 7 & $(0.20)$ & 0.02 & (8.07) & & & & 36 & 0.28 & 2.74 & $(1.80)$ & (7.20) \\
\hline
\end{tabular}

\section{Table A-7A. Results of all regressions}

Table shows complete results for each specification. "Weights" refers to whether the regression is weighted or unweighted. "Method" refers to whether ordinary least squares or median. "Specif" is "Quad" for only a quadratic term, "LinQuad" for quadratic with linear and quadratic terms, "Expon" for non-linear with estimated exponent. The next six columns are coefficients, standard errors of coefficients, and t-statistics of coefficients, $\mathrm{N}$ is number of observations, "Pred at $\mathrm{x}^{\circ} \mathrm{C}$ " is the prediction of each equation at the given temperature increase. 


\begin{tabular}{|c|c|c|c|c|c|c|c|c|c|c|c|c|c|c|c|}
\hline Weights & Method & Specif & $\begin{array}{c}\mathrm{T} \\
\text { spec }\end{array}$ & $\begin{array}{c}\mathrm{T} \\
\text { limit }\end{array}$ & $c(1)$ & se $c(1)$ & $\mathrm{t} c(1)$ & $c(2)$ & se $c(2)$ & $\mathrm{tc}(2)$ & $\mathrm{N}$ & R2bar & $\begin{array}{l}\text { Stand } \\
\text { Err Eq }\end{array}$ & $\begin{array}{c}\text { Pred at } \\
3^{\circ} \mathrm{C}\end{array}$ & $\begin{array}{c}\text { Pred at } \\
6{ }^{\circ} \mathrm{C}\end{array}$ \\
\hline Unweighted & OLS & Quad & $T<=$ & 8 & $(0.21)$ & 0.03 & (7.01) & & & & 37 & 0.33 & 2.72 & (1.90) & (7.59) \\
\hline Unweighted & OLS & Quad & $\mathrm{T}<=$ & 3 & 0.26 & 0.52 & 0.50 & & & & 5 & 0.01 & 1.15 & 2.35 & 9.38 \\
\hline Unweighted & OLS & Quad & $\mathrm{T}<=$ & 4 & $(0.20)$ & 0.01 & (16.21) & & & & 18 & 0.55 & 0.42 & $(1.80)$ & (7.18) \\
\hline Unweighted & OLS & Quad & $\mathrm{T}<=$ & 5 & (0.19) & 0.02 & (10.69) & & & & 30 & 0.25 & 0.94 & (1.72) & (6.89) \\
\hline Unweighted & OLS & Quad & $\mathrm{T}<=$ & 6 & (0.19) & 0.02 & (9.10) & & & & 35 & 0.28 & 1.35 & $(1.74)$ & (6.96) \\
\hline Unweighted & OLS & Quad & $\mathrm{T}<=$ & 7 & $(0.19)$ & 0.02 & (9.33) & & & & 36 & 0.30 & 1.35 & $(1.74)$ & (6.96) \\
\hline Unweighted & OLS & Quad & $\mathrm{T}<=$ & 8 & $(0.23)$ & 0.02 & (13.29) & & & & 37 & 0.71 & 1.47 & (2.09) & (8.38) \\
\hline Unweighted & OLS & Quad & $\mathrm{T}<=$ & 3 & $(0.21)$ & NA & NA & & & & 5 & $(0.05)$ & 1.26 & $(1.90)$ & (7.59) \\
\hline Unweighted & OLS & Quad & $\mathrm{T}<=$ & 4 & $(0.18)$ & 0.03 & (6.51) & & & & 18 & 0.32 & 0.47 & (1.58) & (6.34) \\
\hline Unweighted & OLS & Quad & $\mathrm{T}<=$ & 5 & $(0.18)$ & 0.03 & (5.57) & & & & 30 & 0.16 & 0.95 & (1.58) & (6.34) \\
\hline Unweighted & OLS & Quad & $\mathrm{T}<=$ & 6 & (0.18) & 0.03 & (6.68) & & & & 35 & 0.20 & 1.36 & (1.58) & (6.34) \\
\hline Unweighted & OLS & Quad & $\mathrm{T}<=$ & 7 & $(0.18)$ & 0.02 & (7.38) & & & & 36 & 0.23 & 1.37 & (1.58) & (6.34) \\
\hline Unweighted & OLS & Quad & $\mathrm{T}<=$ & 8 & $(0.20)$ & 0.04 & (5.66) & & & & 37 & 0.33 & 1.54 & $(1.80)$ & (7.20) \\
\hline Unweighted & OLS & LinQuad & $T>=$ & - & $(0.84)$ & 0.29 & (2.89) & $(0.00)$ & 0.05 & $(0.06)$ & 38 & 0.27 & 2.97 & (2.56) & (5.17) \\
\hline Unweighted & OLS & LinQuad & $T>=$ & 1 & $(0.84)$ & 0.29 & (2.89) & $(0.00)$ & 0.05 & $(0.06)$ & 38 & 0.27 & 2.97 & $(2.56)$ & (5.17) \\
\hline Unweighted & OLS & LinQuad & $T>=$ & 2 & $(0.85)$ & 0.30 & (2.81) & $(0.00)$ & 0.05 & $(0.05)$ & 36 & 0.25 & 3.05 & (2.56) & (5.17) \\
\hline Unweighted & OLS & LinQuad & $T>=$ & 3 & $(0.89)$ & 0.31 & (2.83) & 0.00 & 0.05 & 0.06 & 33 & 0.22 & 3.14 & (2.63) & (5.21) \\
\hline Unweighted & OLS & LinQuad & $\mathrm{T}>=$ & 4 & (1.19) & 0.47 & (2.54) & 0.04 & 0.07 & 0.55 & 20 & 0.11 & 3.93 & (3.20) & (5.66) \\
\hline Unweighted & Median & LinQuad & $T>=$ & - & $(0.68)$ & 0.17 & $(4.06)$ & 0.01 & 0.02 & 0.37 & 38 & 0.22 & 3.07 & (1.97) & (3.79) \\
\hline Unweighted & Median & LinQuad & $\mathrm{T}>=$ & 1 & (0.68) & 0.17 & (4.06) & 0.01 & 0.02 & 0.37 & 38 & 0.22 & 3.07 & (1.97) & (3.79) \\
\hline Unweighted & Median & LinQuad & $T>=$ & 2 & $(0.68)$ & 0.18 & (3.78) & 0.01 & 0.02 & 0.34 & 36 & 0.20 & 3.15 & (1.97) & (3.79) \\
\hline Unweighted & Median & LinQuad & $\mathrm{T}>=$ & 3 & $(0.68)$ & 0.18 & (3.69) & 0.01 & 0.02 & 0.33 & 33 & 0.18 & 3.26 & (1.97) & (3.79) \\
\hline Unweighted & Median & LinQuad & $T>=$ & 4 & $(0.81)$ & 0.38 & (2.13) & 0.02 & 0.05 & 0.41 & 20 & 0.11 & 4.11 & (2.25) & (4.11) \\
\hline Weighted & OLS & LinQuad & $\mathrm{T}>=$ & - & 0.06 & 0.17 & 0.36 & $(0.23)$ & 0.05 & $(4.86)$ & 38 & 0.61 & 1.71 & (1.87) & (7.86) \\
\hline Weighted & OLS & LinQuad & $\mathrm{T}>=$ & 1 & 0.06 & 0.17 & 0.36 & $(0.23)$ & 0.05 & (4.86) & 38 & 0.61 & 1.71 & (1.87) & (7.86) \\
\hline Weighted & OLS & LinQuad & $T>=$ & 2 & 0.06 & 0.18 & 0.35 & $(0.23)$ & 0.05 & $(4.72)$ & 36 & 0.61 & 1.69 & (1.87) & (7.86) \\
\hline Weighted & OLS & LinQuad & $\mathrm{T}>=$ & 3 & 0.06 & 0.19 & 0.33 & (0.23) & 0.05 & (4.51) & 33 & 0.61 & 1.66 & (1.87) & (7.86) \\
\hline Weighted & OLS & LinQuad & $T>=$ & 4 & 0.01 & 0.37 & 0.03 & $(0.22)$ & 0.08 & $(2.64)$ & 20 & 0.52 & 2.75 & (1.93) & (7.81) \\
\hline
\end{tabular}

Table A-7B. Results of all regressions

For description, see legend to Table A-7A. 


\begin{tabular}{|c|c|c|c|c|c|c|c|c|c|c|c|c|c|c|c|}
\hline Weights & Method & Specif & $\begin{array}{c}\mathrm{T} \\
\text { spec }\end{array}$ & $\begin{array}{c}\mathrm{T} \\
\text { limit }\end{array}$ & $c(1)$ & se $c(1)$ & $\mathrm{t} c(1)$ & $c(2)$ & se $c(2)$ & $\mathrm{t} \mathrm{c}(2)$ & $\mathrm{N}$ & R2bar & $\begin{array}{l}\text { Stand } \\
\text { Err Eq }\end{array}$ & $\begin{array}{c}\text { Pred at } \\
3{ }^{\circ} \mathrm{C}\end{array}$ & $\begin{array}{c}\text { Pred at } \\
6{ }^{\circ} \mathrm{C}\end{array}$ \\
\hline Weighted & Median & LinQuad & $T>=$ & - & 0.11 & 0.71 & 0.16 & $(0.22)$ & 0.27 & $(0.81)$ & 38 & 0.26 & 1.74 & (1.65) & (7.26) \\
\hline Weighted & Median & LinQuad & $T>=$ & 1 & 0.11 & 0.71 & 0.16 & $(0.22)$ & 0.27 & $(0.81)$ & 38 & 0.26 & 1.74 & (1.65) & (7.26) \\
\hline Weighted & Median & LinQuad & $\mathrm{T}>=$ & 2 & 0.11 & 0.76 & 0.14 & $(0.22)$ & 0.29 & $(0.75)$ & 36 & 0.25 & 1.72 & (1.65) & (7.26) \\
\hline Weighted & Median & LinQuad & $T>=$ & 3 & 0.11 & 0.86 & 0.13 & $(0.22)$ & 0.33 & $(0.66)$ & 33 & 0.24 & 1.69 & (1.65) & (7.26) \\
\hline Weighted & Median & LinQuad & $T>=$ & 4 & 0.40 & 1.60 & 0.25 & $(0.28)$ & 0.46 & $(0.61)$ & 20 & 0.12 & 2.87 & $(1.32)$ & (7.67) \\
\hline Unweighted & OLS & LinQuad & $\mathrm{T}<=$ & 5 & 0.23 & 0.42 & 0.55 & $(0.27)$ & 0.15 & $(1.82)$ & 30 & 0.34 & 1.03 & (1.74) & (8.34) \\
\hline Unweighted & OLS & LinQuad & $\mathrm{T}<=$ & 6 & 1.09 & 0.74 & 1.47 & $(0.60)$ & 0.23 & (2.63) & 35 & 0.30 & 2.65 & (2.17) & $(15.22)$ \\
\hline Unweighted & OLS & LinQuad & $\mathrm{T}<=$ & 7 & 0.34 & 0.56 & 0.60 & $(0.35)$ & 0.16 & (2.17) & 36 & 0.29 & 2.70 & $(2.12)$ & (10.51) \\
\hline Unweighted & OLS & LinQuad & $\mathrm{T}<=$ & 8 & 0.33 & 0.46 & 0.72 & $(0.35)$ & 0.12 & (2.91) & 37 & 0.40 & 2.66 & $(2.12)$ & $(10.45)$ \\
\hline Unweighted & OLS & LinQuad & $T<=$ & 14 & $(0.84)$ & 0.29 & $(2.89)$ & $(0.00)$ & 0.05 & $(0.06)$ & 38 & 0.27 & 2.97 & $(2.56)$ & (5.17) \\
\hline Unweighted & Median & LinQuad & $\mathrm{T}<=$ & 5 & 0.17 & 0.57 & 0.30 & $(0.28)$ & 0.21 & (1.30) & 30 & 0.25 & 1.05 & (1.99) & (8.97) \\
\hline Unweighted & Median & LinQuad & $T<=$ & 6 & $(0.05)$ & 0.46 & $(0.11)$ & $(0.17)$ & 0.16 & (1.06) & 35 & 0.20 & 2.86 & (1.68) & (6.41) \\
\hline Unweighted & Median & LinQuad & $\mathrm{T}<=$ & 7 & 0.02 & 0.25 & 0.09 & $(0.20)$ & 0.07 & (2.94) & 36 & 0.26 & 2.78 & (1.77) & (7.21) \\
\hline Unweighted & Median & LinQuad & $T<=$ & 8 & 0.17 & 0.49 & 0.34 & $(0.28)$ & 0.17 & (1.60) & 37 & 0.31 & 2.69 & (1.99) & (8.97) \\
\hline Unweighted & Median & LinQuad & $\mathrm{T}<=$ & 14 & $(0.68)$ & 0.17 & $(4.06)$ & 0.01 & 0.02 & 0.37 & 38 & 0.22 & 3.07 & (1.97) & (3.79) \\
\hline Weighted & OLS & LinQuad & $\mathrm{T}<=$ & 5 & 0.03 & 0.37 & 0.07 & $(0.20)$ & 0.14 & (1.45) & 30 & 0.22 & 0.96 & (1.73) & (7.08) \\
\hline Weighted & OLS & LinQuad & $\mathrm{T}<=$ & 6 & 0.05 & 0.31 & 0.16 & $(0.21)$ & 0.11 & (1.96) & 35 & 0.26 & 1.37 & (1.74) & (7.27) \\
\hline Weighted & OLS & LinQuad & $\mathrm{T}<=$ & 7 & 0.05 & 0.29 & 0.17 & $(0.21)$ & 0.10 & (2.10) & 36 & 0.28 & 1.37 & (1.74) & (7.27) \\
\hline Weighted & OLS & LinQuad & $T<=$ & 8 & 0.41 & 0.16 & 2.48 & $(0.34)$ & 0.05 & (7.31) & 37 & 0.74 & 1.38 & (1.85) & (9.83) \\
\hline Weighted & OLS & LinQuad & $T<=$ & 14 & 0.06 & 0.17 & 0.36 & $(0.23)$ & 0.05 & $(4.86)$ & 38 & 0.61 & 1.71 & (1.87) & (7.86) \\
\hline Weighted & Median & LinQuad & $\mathrm{T}<=$ & 5 & 0.33 & 0.46 & 0.73 & (0.31) & 0.20 & (1.53) & 30 & 0.14 & 0.97 & (1.78) & (9.14) \\
\hline Weighted & Median & LinQuad & $T<=$ & 6 & (0.09) & 0.27 & $(0.32)$ & $(0.14)$ & 0.09 & (1.50) & 35 & 0.18 & 1.39 & (1.53) & (5.62) \\
\hline Weighted & Median & LinQuad & $\mathrm{T}<=$ & 7 & 0.04 & 0.23 & 0.16 & (0.19) & 0.08 & $(2.28)$ & 36 & 0.21 & 1.38 & (1.61) & (6.66) \\
\hline Weighted & Median & LinQuad & $\mathrm{T}<=$ & 8 & 0.43 & 0.12 & 3.61 & $(0.36)$ & 0.03 & $(13.33)$ & 37 & 0.37 & 1.39 & (1.95) & $(10.40)$ \\
\hline Weighted & Median & LinQuad & $\mathrm{T}<=$ & 14 & 0.11 & 0.71 & 0.16 & $(0.22)$ & 0.27 & $(0.81)$ & 38 & 0.26 & 1.74 & (1.65) & (7.26) \\
\hline Unweighted & NLS & Expon & AllT & 14 & (0.69) & 0.35 & (1.99) & 1.15 & 0.30 & 3.80 & 38 & 0.27 & 2.95 & (2.43) & (5.38) \\
\hline Weighted & NLS & Expon & AllT & 14 & $(0.20)$ & 0.03 & (6.35) & 2.06 & 0.13 & 16.44 & 38 & 0.61 & 1.72 & (1.89) & (7.88) \\
\hline Unweighted & NLS & Expon & AllT & 14 & $(2.66)$ & 3.24 & $(0.82)$ & 0.68 & 0.45 & 1.49 & 38 & 0.29 & 2.92 & $(2.47)$ & (5.85) \\
\hline Weighted & NLS & Expon & AllT & 14 & (0.99) & 0.58 & (1.70) & 1.32 & 0.29 & 4.48 & 38 & 0.63 & 1.67 & $(2.04)$ & (8.36) \\
\hline
\end{tabular}

Table A-7C. Results of all regressions

For description, see legend to Table A-7A. 


\section{Appendix B. Source of additional damages}

The following is drawn from Nordhaus and Sztorc (2013).

"The 2013 model instead uses a highly simplified damage function that relies on current estimates of the damage function. More precisely, DICE-2013R uses estimates of monetized damages from the Tol (2009) survey as the starting point. However, current studies generally omit several important factors (the economic value of losses from biodiversity, ocean acidification, and political reactions), extreme events (sea-level rise, changes in ocean circulation, and accelerated climate change), impacts that are inherently difficult to model (catastrophic events and very long term warming), and uncertainty (of virtually all components from economic growth to damages). I have added an adjustment of 25 percent of the monetized damages to reflect these non-monetized impacts. While this is consistent with the estimates from other studies (see Hope 2011, Anthoff and Tol 2010, and FUND 2013), it is recognized that this is largely a judgmental adjustment. The current version assumes that damages are a quadratic function of temperature change and does not include sharp thresholds or tipping points, but this is consistent with the survey by Lenton et al. (2008)." (p.11) 


\section{References}

Betts, R. A., Collins, M., Hemming, D. L., Jones, C. D., Lowe, J. A., \& Sanderson, M. G. (2011). When could global warming reach $4^{\circ} \mathrm{C}$ ? Philosophical Transactions of the Royal Society of London A: Mathematical, Physical and Engineering Sciences, 369(1934), 67-84. http://doi.org/10.1098/rsta.2010.0292

Bosello, Francesco, Fabio Eboli, and Roberta Pierfederici. 2012. "Assessing the Economic Impacts of Climate Change." Review of Environment Energy and Economics, February 10.

Card, David and Alan B. Krueger. 1995. "Time-Series Minimum-Wage Studies: A Metaanalysis," The American Economic Review, 85(2), 238-243

Editorial Note. 2015. "Editorial Note: Correction to Richard S. Tol's 'The Economic Effects of Climate Change'," Journal of Economic Perspectives, vol. 29, no. 1, Winter, 217-20.

Fankhauser, Samuel. 1995. Valuing Climate Change-The Economics of the Greenhouse, 1st edition. London: EarthScan.

Gillingham, Kenneth, William D. Nordhaus, David Anthoff, Geoffrey Blanford, Valentina Bosetti, Peter Christensen, Haewon McJeon, John Reilly, and Paul Sztorc. 2015. “Modeling Uncertainty in Climate Change: A Multi-Model Comparison." No. w21637. National Bureau of Economic Research.

Hope, Chris. 2006. "The Marginal Impact of CO2 from PAGE2002: An Integrated Assessment Model Incorporating the IPCC's Five Reasons for Concern." Integrated Assessment Journal 6(1): 19 -56.

Ioannidis, John P. A. 2016. “Why Most Clinical Research Is Not Useful,” PLOS, 13(6), p.e1002049.

IPCC, Impacts. 2007. Intergovernmental Panel on Climate Change, Climate Change 2007Impacts, Adaptation and Vulnerability. Cambridge, UK: Cambridge University Press.

IPCC, Impacts. 2014. Intergovernmental Panel on Climate Change, Climate Change 2014Impacts, Adaptation and Vulnerability: Regional Aspects. New York: Cambridge University Press.

IPCC WGII AR5 Chapter 10, Final Draft. Retrieved April 28, 2016, from http://ipccwg2.gov/AR5/images/uploads/WGIIAR5-Chap10_FGDall.pdf

Maddison, David. 2003. "The Amenity Value of the Climate: The Household Production Function Approach." Resource and Energy Economics 25(2): 155 -75.

Maddison, David, and Katrin Rehdanz. 2005. Climate and Happiness, Ecological Economics, 55(1).

Maddison, David, and Katrin Rehdanz. 2011. "The Impact of Climate on Life Satisfaction." Ecological Economics 70(12): 2437- 45. 
Mendelsohn, Robert, Wendy Morrison, Michael E. Schlesinger, and Natalia G. Andronova. 2000. "Country-Specific Market Impacts of Climate Change." Climatic Change 45(3 -4): $553-69$.

Mendelsohn, Robert O., Michael E. Schlesinger, and Lawrence J. Williams. 2000. “Comparing Impacts across Climate Models." Integrated Assessment, 1(1): 37-48.

National Research Council. 2017. Valuing Climate Damages: Updating Estimation of the Social Cost of Carbon Dioxide, Report of the Committee on Assessing Approaches to Updating the Social Cost of Carbon, National Academy Press: Washington, D.C.

Nordhaus, William D. 1994a. "Expert Opinion on Climate Change." American Scientist 82(1): $45-51$.

Nordhaus, William D. 1994b. Managing the Global Commons: The Economics of Climate Change. Cambridge. The MIT Press.

Nordhaus, William D. 2006. “Geography and Macroeconomics: New Data and New Findings." Proceedings of the National Academy of Science 103(10): 3510 -17.

Nordhaus, William D. 2008. A Question of Balance-Weighing the Options on Global Warming Policies. New Haven: Yale University Press.

Nordhaus, William D. 2013. The Climate Casino-Risk, Uncertainty, and Economics for a Warming World. New Haven: Yale University Press.

Nordhaus, William D., and Joseph Boyer. 2000. Warming the World: Economic Models of Global Warming. The MIT Press.

Nordhaus, William and Paul Sztorc. 2013. DICE 2013R: Introduction and User's Manual, October 2013, available at http://www.econ.yale.edu/ nordhaus/homepage/ documents/DICE_Manual_100413r1.pdf.

Nordhaus, William D., and Zili Yang. 1996. “A regional dynamic general-equilibrium model of alternative climate-change strategies” American Economic Review 86(4): 74165.

Plambeck, Erica L., and Chris Hope. 1996. "PAGE95-An Updated Valuation of the Impacts of Global Warming.” Energy Policy 24(9): 783 -93.

Pearson, K. 1904. "Report on certain enteric fever inoculation statistics." BMJ 3:12431246.

Rehdanz, Katrin, and David J. Maddison. 2005. “Climate and Happiness.” Ecological Economics 52(1): 111-25.

Roson, Roberto, and Dominique Van der Mensbrugghe. 2012. "Climate Change and Economic Growth: Impacts and Interactions." International Journal of Sustainable Economy 4(3): 270-85.

Stanley, T.D. 1998. "New Wine in Old Bottles: A Meta-Analysis of Ricardian Equivalence," Southern Economic Journal, 64 (3) 713-727. 
Stanley, T.D. 2001. "Wheat from Chaff: Meta-Analysis as Quantitative Literature Review," The Journal of Economic Perspectives, 15 (3), 131-150

Stanley, T.D. and Doucouliagos, H. (C.)(2012) Meta-Regression Analysis in Economics and Business. Oxford: Routledge.

T.D. Stanley, H. Doucouliagos, M. Giles, J.H. Heckemeyer, R.J. Johnston, P. Laroche, J.P. Nelson, M. Paldam, J. Poot, G. Pugh, R.S. Rosenberger, K. Rost. 2013. "Meta-analysis of economics research reporting guidelines." Journal of Economic Surveys, 27 (2) (2013), pp. 390-394. Available at: http://onlinelibrary.wiley.com/doi/10.1111/joes.12008/full

Tol, Richard S. J. 1995. "The Damage Costs of Climate Change toward More Comprehensive Calculations." Environmental and Resource Economics 5(4): 353 -74.

Tol, Richard S. J. 2002. "Estimates of the Damage Costs of Climate Change-Part I: Benchmark Estimates." Environmental and Resource Economics 21(1): 47-73.

Tol, Richard S. J. 2009. "The Economic Effects of Climate Change." Journal of Economic Perspectives 23(2): $29-51$.

Tol, Richard S. J. 2014. "Correction and Update: The Economic Effects of Climate Change" Journal of Economic Perspectives, 28(2), 221-26.

Tol, R., \& Anthoff, D. (2014, August 28). FUND Technical Tables. Retrieved May 25, 2016.

Ward, R. (2014a, April 15). Errors in estimates of the aggregate economic impacts of climate change | Grantham Research Institute on climate change and the environment. Retrieved from http://www.lse.ac.uk/GranthamInstitute/news/errors-in-estimates-ofthe-aggregate-economic-impacts-of-climate-change/

Ward, R. (2014b, April 15). Errors in estimates of the aggregate economic impacts of climate change - Part II | Grantham Research Institute on climate change and the environment. Retrieved from http://www.lse.ac.uk/GranthamInstitute/news/errors-inestimates-of-the-aggregate-economic-impacts-of-climate-change-part-ii/

Ward and Van Der Mensbrugghe Email Correspondence. Retrieved April 28, 2016, from http://www.lse.ac.uk/GranthamInstitute/wp-content/uploads/2014/05/Van-derMensbrugghe-email-exchange-January-2014.pdf

Why climate change is good for the world. (2013, October 19). Retrieved from http://www.spectator.co.uk/2013/10/carry-on-warming/ 